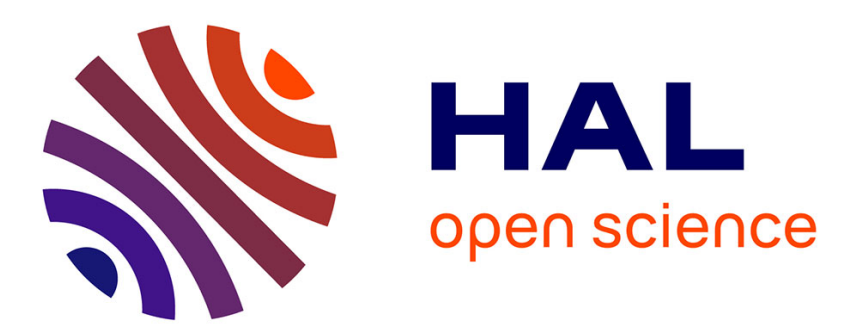

\title{
A comparative study of various parameterizations of the planetary boundary layer in a numerical mesoscale model
}

J.-F. Mahfouf, Evelyne Richard, Patrick Mascart, E. C. Nickerson, R. Rosset

\section{- To cite this version:}

J.-F. Mahfouf, Evelyne Richard, Patrick Mascart, E. C. Nickerson, R. Rosset. A comparative study of various parameterizations of the planetary boundary layer in a numerical mesoscale model. Journal of Climate and Applied Meteorology, 1987, pp.1671-1695. hal-01983104

\section{HAL Id: hal-01983104 \\ https://hal.uca.fr/hal-01983104}

Submitted on 3 Dec 2021

HAL is a multi-disciplinary open access archive for the deposit and dissemination of scientific research documents, whether they are published or not. The documents may come from teaching and research institutions in France or abroad, or from public or private research centers.
L'archive ouverte pluridisciplinaire HAL, est destinée au dépôt et à la diffusion de documents scientifiques de niveau recherche, publiés ou non, émanant des établissements d'enseignement et de recherche français ou étrangers, des laboratoires publics ou privés.

$$
\text { Copyright }
$$




\title{
A Comparative Study of Various Parameterizations of the Planetary Boundary Layer in a Numerical Mesoscale Model
}

\author{
J. F. MAHFOUF*, E. RICHARD*, P. MASCART*, E. C. NICKERSON ${ }^{\dagger}$ AND R. ROSSET* \\ *OPGC/LAMP, 63000 Clermont-Ferrand, France \\ ${ }^{\dagger}$ NOAA/Environmental Research Laboratory, Boulder, CO 80303
}

(Manuscript received 6 November 1986, in final form 23 May 1987)

\begin{abstract}
Various parameterizations of the planetary boundary layer (PBL) currently used in three-dimensional (3D) mesoscale models are compared with a more complex scheme including a turbulent kinetic energy (TKE) equation. In the first set of simulations made with a 1D model against the classical Wangara data, the mean wind, temperature and moisture calculated in the PBL are nearly insensitive to the choice of the parameterization. In the second set of simulations, the TKE parameterization is used in a 3D mesoscale model to simulate sea breeze flows over south Florida. A comparison is presented with previous simulations of Pielke, and Pielke and Mahrer, for the mean flow, and with the third-order turbulence closure model of Brière for the turbulent variables, including a discussion of the turbulent energy budget. The analysis of the results obtained with the TKE scheme shows that the predicted turbulent fields are qualitatively realistic and interact significantly with the sea breeze circulation. Finally, a comparison is made between the TKE scheme and the simpler parameterization of Pielke and Mahrer. It shows only slight differences as far as the mesoscale structure of the mean variables is concerned.
\end{abstract}

\section{Introduction}

Most mesoscale flows are more or less modified by the diurnal variations of the heat, moisture and momentum fluxes occurring within the planetary boundary layer (PBL) and at the soil surface. For instance, Anthes (1984) and Pielke (1984) emphasized the meso$\beta$ scale (20-200 km; Orlanski, 1975) generated by landsurface inhomogeneities. An accurate parameterization of the planetary boundary layer and of the changes in the thermal and moisture of the soil properties is, therefore, essential if the lower atmosphere is to be simulated properly in a $\beta$-mesoscale model. During the past $10 \mathrm{yr}$, the simulation of the planetary boundary layer has received much attention and a wide set of models is now available. It is difficult, however, to make an optimal choice between all these models which are broadly different and sometimes contradictory in nature. A first class of models treats the PBL as a single mixed layer, as done for example by Lavoie (1972) and Keyser and Anthes (1977). This simple and computationally efficient technique is extreme, however, in that it allows no structure in the vertical. A possible improvement is to partition the PBL in a few sublayers over which the governing equations are integrated, after specifying the profile shapes according to the turbulent regime. This approach was used by Zeman (1979) for the nocturnal PBL and is recommended by Wyngaard (1984) for scalars in the convective PBL.

An alternative is to use a multilevel PBL model having many grid points in the vertical. The major advan- tages of using a multilevel PBL parameterization in a $\beta$-mesoscale model were discussed by Anthes et al. $(1980,1982)$. These authors showed that detailed boundary layer resolution is essential when differential heating along complex terrain and across land-water boundaries is being represented, since significant vertical gradients of the meteorological variables occur within the PBL. However, many of these high resolution PBL models use very simple turbulence closure schemes-for instance, prescribed eddy exchange coefficients-which have serious deficiencies such as the inability to reproduce fluxes in convective layers (Wyngaard, 1984). A second possibility is therefore to resort to higher-order turbulence closures which are much less restrictive and were successfully used in 1D models, for example, to simulate the 24-h evolution of the PBL (Yamada and Mellor, 1975; André et al., 1978) and subsequently applied to cloudy PBL (Mellor, 1977; Bougeault, 1981). In spite of the cost and complexity of these techniques, multidimensional mesoscale simulations were performed by Sun and Ogura (1979), using a second-order closure, and Brière (1987) using a third-order closure.

Finally, a third interesting new possibility of multilevel parameterization is emerging with nonlocal closures, such as the integral closure of Fiedler (1984) and the transilient turbulent theory of Stull (1984) and Stull and Hasegawa (1984). In these theories, a different mixing parameter is used for each eddy size, leading to a nonlocal first-order technique to determine the turbulent fluxes. As shown by Stull (1986), a simplified

(C) 1987 American Meteorological Society 
scheme of this type was proposed by Blackadar (1978) and tested by Zhang and Anthes (1982). This scheme is used by Zhang and Fritsch (1986) to model the heat and momentum turbulent transports in the three-dimensional NCAR-PSU mesoscale model.

In this paper, we consider a multilevel PBL parameterization of intermediate complexity, based on the improved turbulent kinetic energy (TKE) model of Therry and Lacarrère (1983). The advantage of this TKE model is that it accounts for some improvements inferred from second-order closure models, while keeping most of the computational efficiency of simpler $\mathrm{K}$-models (implicit numerical schemes). The turbulent fluxes and the mean structure of the PBL predicted by this parameterization are compared with those obtained using two other multilevel parameterizations currently used in 3D mesoscale models in order to study whether the TKE scheme provides a significantly improved atmospheric response in two different physical situations. In section 2 we consider the simple situation of horizontal homogeneity to compare the TKE method with the Zhang and Anthes (1982) and the Pielke and Mahrer (1975) models, all three models being used in conjunction with the same radiation and soil package. Checking a reasonable agreement against this simple situation was regarded as a prerequisite for further use under more complex conditions and where a comprehensive set of observations is not available. In section 3 a second set of comparisons is made under horizontally inhomogeneous surface forcing using the three-dimensional mesoscale model of Nickerson et al. (1986) to simulate a sea breeze flow over south Florida. First, the results obtained using the Therry and Lacarrère TKE parameterization are presented and the connections between the predicted TKE field and the sea breeze flow are discussed by examining each term of the TKE budget. Due to the lack of mesoscale statistics of the turbulence structure over Florida, a comparison with observed data is not attempted. However, a comparison is made with the very detailed sea breeze simulation of Brière (1987), who uses a third-order turbulence closure model, and a good qualitative agreement is obtained for the broad features of the TKE budget within the different regions of the sea breeze circulation. Finally, the circulations predicted using the TKE scheme and those obtained with the Pielke and Mahrer (1975) parameterization are compared and only minor differences are found in the mean flow (nonturbulent) characteristics.

\section{Comparisons under horizontally homogeneous con- ditions}

In this section, a one-dimensional PBL model is considered to compare the solutions obtained using the TKE parameterization and two different techniques. To make this comparison, the well-known day 33 of the Wangara Experiment (Clarke et al., 1971) is used. Checking quantitatively, the consistency of the parameterizations under identical forcing conditions is a mandatory step before any discussion of more complex three-dimensional simulations is undertaken.

\section{a. Basic equations}

The rate equations for the mean wind components $u, v$, potential temperature $\theta$ and water vapor mixing ratio $q$ above the surface layer are given by

$$
\begin{aligned}
& \frac{\partial u}{\partial t}=-\frac{\partial}{\partial z}\left(\overline{w^{\prime} u^{\prime}}\right)+f\left(v-v_{g}\right), \\
& \frac{\partial v}{\partial t}=-\frac{\partial}{\partial z}\left(\overline{w^{\prime} v^{\prime}}\right)-f\left(u-u_{g}\right), \\
& \frac{\partial \theta}{\partial t}=-\frac{\partial}{\partial z}\left(\overline{w^{\prime} \theta^{\prime}}\right)+\left.\frac{\partial \theta}{\partial t}\right|_{\mathrm{ad} v}, \\
& \frac{\partial q}{\partial t}=-\frac{\partial}{\partial z}\left(\overline{w^{\prime} q^{\prime}}\right)
\end{aligned}
$$

where $u_{g}$ and $v_{g}$ are the components of the geostrophic wind, and $f$ the Coriolis parameter $\left(-8.26 \times 10^{-5} \mathrm{~s}^{-1}\right.$ for Wangara). The radiational effects are included only at the ground since the present comparison is mainly limited to daytime. The last term in (3) accounts for the large-scale changes of temperature, as estimated from the Wangara handbook. The formulations used for the momentum, heat and moisture fluxes in (1)(4) are given later.

The lower boundary conditions for the atmospheric model are provided by computing the fluxes within the surface layer, using the surface layer similarity theory as formulated by Businger (1973) and Nickerson and Smiley (1975). The required values for the ground temperature and moisture are obtained from a multilevel soil model coupled to the surface layer through budget equations for heat and moisture. The techniques used for this soil package are identical to the bare soil model of McCumber and Pielke (1981). The incoming solar radiation and the net longwave radiation are computed from the simple scheme of Zhang and Anthes (1982), which seemed sufficient for the present purpose, using a constant ground albedo of 0.2 and an atmospheric transmittivity of 0.9 .

\section{b. Turbulent fluxes}

As previously stated, three different parameterization schemes are compared. They are referred to as formulations A, B and C in Table 1.

Formulation A, proposed by Therry and Lacarrère (1983), expresses the turbulent fluxes through an eddy diffusivity assumption,

$$
\overline{w^{\prime} u^{\prime}}=-K_{M} \frac{\partial u}{\partial z},
$$


TABLE 1. The PBL characteristics in the ID experiments.

\begin{tabular}{ccccc}
\hline \hline Formulation & Vertical diffusion & Mixed layer depth & $\begin{array}{c}\text { Turbulent energy } \\
\text { equation }\end{array}$ & References \\
\hline A & $\begin{array}{c}\text { Exchange coefficients } \\
K=0.5 l_{K} e^{1 / 2}\end{array}$ & $\begin{array}{c}\text { Diagnosed from the heat } \\
\text { fluxes profiles }\end{array}$ & Prognostic Eq. (9) & Therry and Lacarrère (1983) \\
B & $\begin{array}{c}\text { Exchange coefficients } \\
\text { (O'Brien, 1970) }\end{array}$ & $\begin{array}{c}\text { Prognostic equation } \\
\text { (Deardorff, 1974) }\end{array}$ & None & Pielke and Mahrer (1975) \\
C & $\begin{array}{c}\text { Mixed layer model } \\
\text { (Blackadar, 1978) }\end{array}$ & $\begin{array}{c}\text { Computed from the } \\
\text { mixed layer model }\end{array}$ & None & Zhang and Anthes (1982) \\
\hline
\end{tabular}

$$
\begin{aligned}
& \overline{w^{\prime} v^{\prime}}=-K_{M} \frac{\partial v}{\partial z} \\
& \overline{w^{\prime} \theta^{\prime}}=-K_{H}\left(\frac{\partial \theta}{\partial z}-\gamma_{c g}\right), \\
& \overline{w^{\prime} q^{\prime}}=-K_{H} \frac{\partial q}{\partial z}
\end{aligned}
$$

where the exchange coefficients, $K_{M}=0.5 l_{K} e^{1 / 2}$ and $K_{H}=1.35 K_{M}$, are related to the TKE, $e$, being calculated from its rate equation,

$$
\begin{aligned}
\frac{\partial e}{\partial t}=\frac{\partial}{\partial z}\left(1.3 K_{M} \frac{\partial e}{\partial z}\right) & +K_{M}\left[\left(\frac{\partial u}{\partial z}\right)^{2}+\left(\frac{\partial v}{\partial z}\right)^{2}\right] \\
& -\frac{g}{\theta_{0}} K_{H}\left(\frac{\partial \theta_{v}}{\partial z}-\gamma_{c g}\right)-0.125 \frac{e^{3 / 2}}{l_{\varepsilon}}
\end{aligned}
$$

In order to minimize the systematic shortcomings resulting from the use of exchange coefficients, the model includes three improvements derived by Therry and Lacarrère (1983) from a systematic order-of-magnitude analysis of the rate equations for the second-order moments computed in the third-order model of André et al. (1978). First, a distinction is made in (9) between mixing length, $l_{K}$, and dissipation length, $l_{c}$, the ratio of which is proportional to $\overline{w^{\prime 2}} / e$ (with $l_{K}>l_{c}$ ) and parameterized in terms of altitude and stability. This refinement minimizes a well-known deficiency of TKE models, which tends to underestimate the mixing and therefore the convective PBL growth rate. Second, the dissipation length (which can be estimated using TKE and its dissipation rate) is parameterized in terms of surface layer regime, altitude and local stability using the large eddy simulation results of Deardorff (1974). Third, a temperature countergradient, $\gamma_{c g}$, proportional to $\theta^{2} / w^{\prime 2}$ is derived from a simplified analysis of the heat flux rate equation inferred from André et al. (1978), and parameterized as $5 Q_{0} / w_{*} Z_{i}$. A similar improvement is possible for the TKE fluxes in (9), but is not included in the present version of our model. One interesting feature with the above formulation is that it is neither very expensive in computation time nor difficult to implement in a 3D model because it involves only one extra prognostic equation for $e$ and also uses the exchange coefficient formalism, which easily allows an implicit treatment of the diffusion terms in (5)-(9).

Formulation B was proposed by Pielke and Mahrer (1975) and McNider and Pielke (1981). This parameterization involves two modules corresponding respectively to stable and unstable turbulence regimes for the surface layer. Both modules employ the exchange coefficient formalism. For stable conditions, the exchange coefficients are related to the local gradient Richardson number, after Blackadar (1976). For the growing convective boundary layer, the model employs the cubic polynomial formulation suggested by $O$ 'Brien (1970) for the vertical exchange coefficients. The depth of the PBL, $Z_{i}$, required to calculate the O'Brien polynomials, is computed from the rate equation of Deardorff (1974). The thickness of surface layer is estimated from $Z_{i}$, after Pielke and Mahrer (1975), as $h=0.04 Z_{i}$.

Formulation $\mathrm{C}$ was taken from Zhang and Anthes (1982). This model is also subdivided into two modules for stable and unstable conditions. The nighttime (stable) module is nearly identical to model $B$. The daytime (unstable) module is a mixed layer model proposed by Blackadar (1978), in which the heat exchange between the surface and the PBL is schematically operated by thermals ascending from the surface layer. The mixing intensity in the neutral layer is related to a constant mass exchange rate between any level and the surface, the temperature of which is calculated from the free convective equation of Priestley (1957).

\section{c. Preliminary discussion of the selected formulations}

Out of the wide range of choices summarized in the Introduction, formulations A, B and C were selected with the main rationale being that they were of intermediate complexity and affordable in a multidimensional mesoscale model. In this section, we present a brief discussion of the main physical properties of the above-mentioned formulations, with the help of Table 2. The purpose of this discussion is to emphasize their respective similarities or differences in order to anticipate how they could respond to meteorological forcings. We realize, however, that the choice of the criteria 
TABLE 2. Tentative comparison of formulations A, B and C in terms of their overall properties.

\begin{tabular}{|c|c|c|c|}
\hline Property & Model A & Model B & Model C \\
\hline \multicolumn{4}{|l|}{ Turbulence production } \\
\hline Buoyancy & yes & 'yes & yes \\
\hline Shear & explicit & no & no \\
\hline Advective effects & yes & PBL depth only & no \\
\hline \multicolumn{4}{|l|}{ Fluxes in convective layers } \\
\hline $\begin{array}{l}\text { Heat } \\
\text { Turbulent energy }\end{array}$ & $\begin{array}{l}\text { corrected gradient transport } \\
\text { local gradient transport }\end{array}$ & local gradient transport & nonlocal mixing parameter \\
\hline Other variables & local gradient transport & local gradient transport & nonlocal mixing parameter \\
\hline $\begin{array}{l}\text { Turbulence extinction in } \\
\text { stable layers }\end{array}$ & $\mathrm{Ri}_{c} \geqslant 0.4$ & $\begin{array}{l}\mathrm{Ri} \geqslant 0.6 \\
(\Delta z \# 100 \mathrm{~m})\end{array}$ & $\begin{array}{l}\mathrm{Ri} \geqslant 0.6 \\
(\Delta z \# 100 \mathrm{~m})\end{array}$ \\
\hline
\end{tabular}

listed in Table 2 is largely subjective and not comprehensive.

First, we consider the contributions to turbulence generation. All three models allow for mixing induced by buoyancy. However, the techniques used are very different, and this might imply specific deficiencies which are subsequently discussed. Regarding the turbulence production by the shear of the mean wind profile, only model $\mathrm{A}$ includes this effect explicitly. In model $\mathrm{B}$, the wind shear is very indirectly present in the rate equation for the PBL depth, which contains the friction velocity. Different responses might therefore be expected in strongly sheared boundary layer situations such as, for example, surface fronts, sea breezes and orographic flows. Another potentially important source of differences could arise from advection effects. In model $\mathrm{A}$, advection directly modifies the turbulence kinetic energy (9). In model B, the PBL depth is modified by advection under convective conditions.

A very important point for all the models relates to their response in the convective case. This case is of great meteorological significance since it corresponds to large heat fluxes and is closely related to the triggering of convection. As shown, for example, by Wyngaard (1984), gradient transport formalism used in model B for all variables predicts inaccurately the vertical gradients in convective layers, with potentially larger errors for humidity. Model C, which uses a nonlocal scheme is, in principle, free of these shortcomings. However, the weighting function prescribed to parameterize the vertical mixing is quite arbitrary and prone to substantial errors near the top of the mixed layer (Zhang and Fritsch, 1986). Model $A$ includes a specific correction, $\gamma_{c g}$, for the heat flux, which should improve the vertical gradient of the temperature in convective layers. However, this correction is absent for other variables. It is, therefore, interesting to check the consistency of the models under strongly convective conditions.

Finally, it is known that in stable conditions the turbulence should die out when the Richardson number becomes larger than a critical value. All three models include this effect, either explicitly (model A), or through the use of a specific module for stable conditions (the same for models B and C). The values of the critical Richardson numbers are somewhat different, but this is not highly significant in the present practical context.

Thus, the conclusion of our preliminary examination of $\mathrm{A}, \mathrm{B}$ and $\mathrm{C}$ schemes is that 1) their consistency is to be examined under strongly convective conditions, and 2) model A might provide improved results when both the vertical wind shear and the buoyancy are simultaneously contributing to the turbulence. The first point is addressed in the present section and consideration of the second one is postponed until section 3 .

\section{d. Initial conditions and numerical procedures}

The initial conditions for all simulations were taken from Wangara day 33 at 0900 LST following the procedure used by Yamada and Mellor (1975) except for the synoptic vertical motion, which was set equal to zero. With respect to the soil layer, Clarke et al. (1971) describe it as a dry layer of loam overlying a deeper layer of clay. Vegetation is nearly negligible. Accordingly, we initialized the model's soil layer using the soil parameter table of Clapp and Hornberger (1978) for a homogeneous layer of loamy clay with a volumetric moisture content close to the wilting point.

The vertical grid used in the atmosphere is vertically staggered with 30 levels between 0 and $2 \mathrm{~km}$. The mesh size is $10 \mathrm{~m}$ near the surface and slowly increasing upwards, its average value being $30 \mathrm{~m}$. The vertical grid in the soil layer is logarithmic with 13 levels in the first meter. The mesh size has to be very small near the surface, of the order of $1 \mathrm{~mm}$, with the average being $15 \mathrm{~cm}$. The finite difference scheme used for both the atmosphere and soil is implicit. The budget equations at the surface are solved by an iterative procedure with a time step of $180 \mathrm{~s}$.

\section{e. Results}

In Fig. 1, the curves of time evolution of the computed surface temperature (dashed lines) and screen 


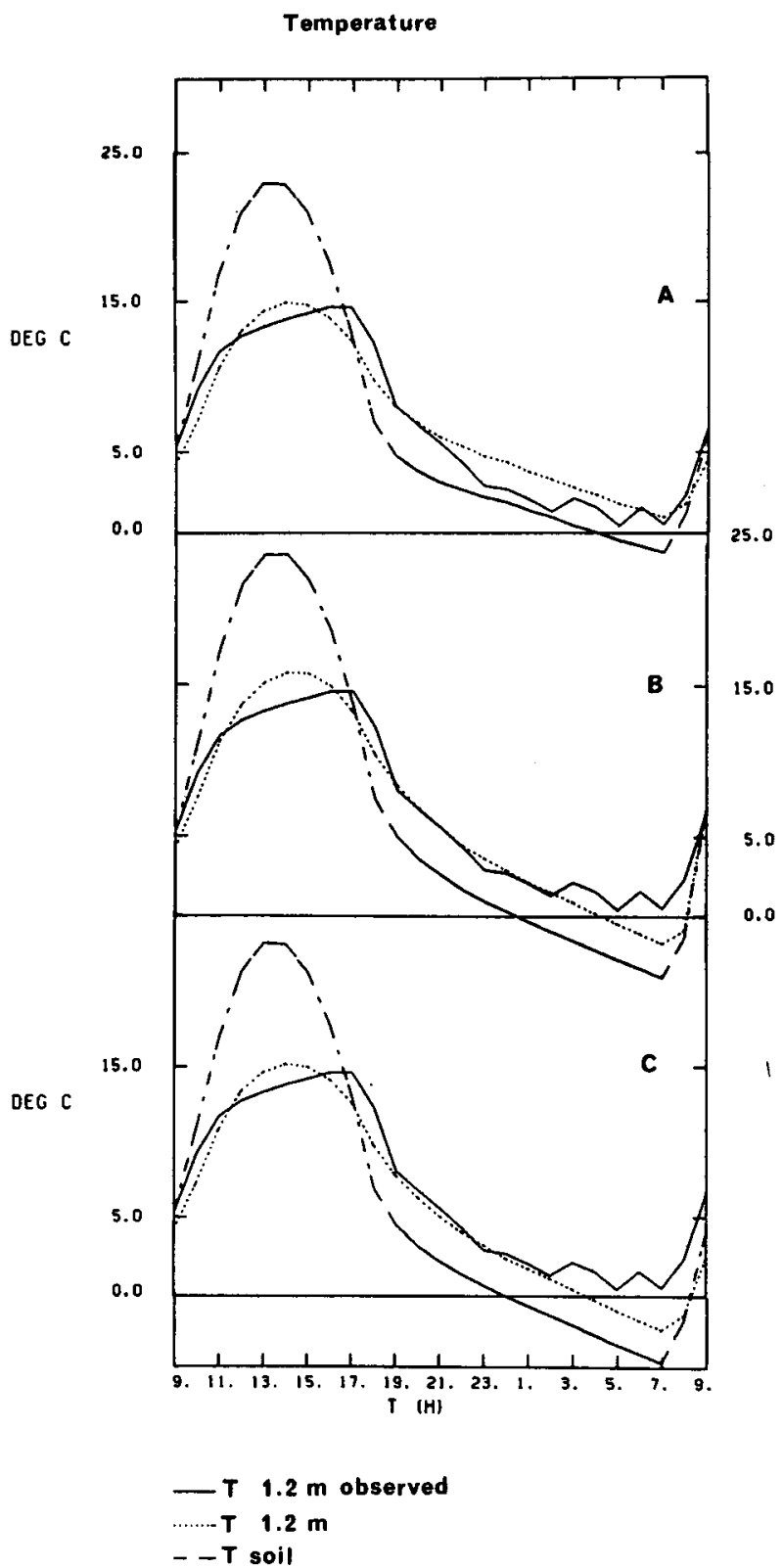

FIG. 1. Time variation during day 33 of the observed (solid lines) and computed (dotted lines) temperature at screen height $(1.2 \mathrm{~m})$ and of the computed ground temperature (dashed lines).

level temperature (dotted lines) obtained during a 24h simulation with models $\mathrm{A}, \mathrm{B}$ and $\mathrm{C}$ are compared. The observed screen level temperature (solid lines) is also shown in these diagrams. The screen level temperature ( $1.2 \mathrm{~m}$ above the ground) is calculated from surface and $10 \mathrm{~m}$ values through the surface layer similarity. This temperature was used as a driving parameter for the surface heat flux computations in several previous works (Yamada and Mellor, 1975; André et al., 1978). A quite similar behavior is found during daytime for the three models. Subsequently, during nighttime, between 0100 and 0900 LST, models B and $C$ underestimate the screen level temperature, whereas a better agreement is found with model $\mathrm{A}$. These differences in the early morning of day 34 are probably related to the absence of the atmospheric radiative cooling.

In Fig. 2, the evolution of the mean potential temperature computed with models $\mathrm{A}, \mathrm{B}$ and $\mathrm{C}$ is compared with the observed data. The well-known development of the mixed layer is recovered and the results are nearly identical for the three models. Only minor differences appear in the "overshoot" region near the PBL top, more noticeable in model A. The mixed layer depth as predicted by the three models and the one observed (open squares) are shown in Fig. 3 but it is worth noting that the PBL depth definitions are not exactly the same in the three models. With the TKE model (A), this depth is defined as the level where the sensible heat flux is minimum (Deardorff, 1974) whereas, in models B and C, the mixed layer depth is an explicit component of the daytime package, computed from a rate equation for model $B$, and from a given partition of the buoyant energy for model C. As seen in Fig. 3, similar growth of the mixed layer is predicted by all three models between 0900 LST and $1700 \mathrm{LST}$ and is in good agreement with the observations. For most of the time, the scatter is less than $100 \mathrm{~m}$ between any predicted value and the observed average depth (taken from Fig. 6 of Deardorff, 1974), with model A giving systematically smaller depths. After 1700 LST, the prediction of model A significantly differs from both models $B$ and $C$. The sharp decrease in PBL depth in model A is directly related to the turbulent intensity in the PBL. As the surface sensible heat flux becomes negative a few minutes before the sunset (at about 1730 LST), the model switches abruptly from the depth of the mixed layer to the depth of the stable layer near the ground. With models B and $\mathrm{C}$, a switch between the convective and stable packages also occurs at about 1730 LST but the PBL depth, not used by the stable package, is not updated. The difference seen in Fig. 3 at 1800 LST is therefore an artifact of the computation.

The predicted and observed mean horizontal wind speeds are presented in Fig. 4. All the profiles show a nearly constant wind speed in the mixed layer. After a decrease during morning hours, the wind speed strengthens significantly between 1200 and 1800 LST. As can be seen above the mixed layer, where the turbulent fluxes are negligible, this trend is mainly due to large scales. A reasonable agreement is found between the computed and observed profiles, the scatter being of the order of $1 \mathrm{~m} \mathrm{~s}^{-1}$, but systematic differences appear between the three models. Model C overestimates the wind speed maximum near the ground by about 2 $\mathrm{m} \mathrm{s}^{-1}$ at $1800 \mathrm{LST}$, whereas model B severely smooths the profile near the top of the PBL. As seen in Fig. 5, the comparison between the eddy exchange coefficients 

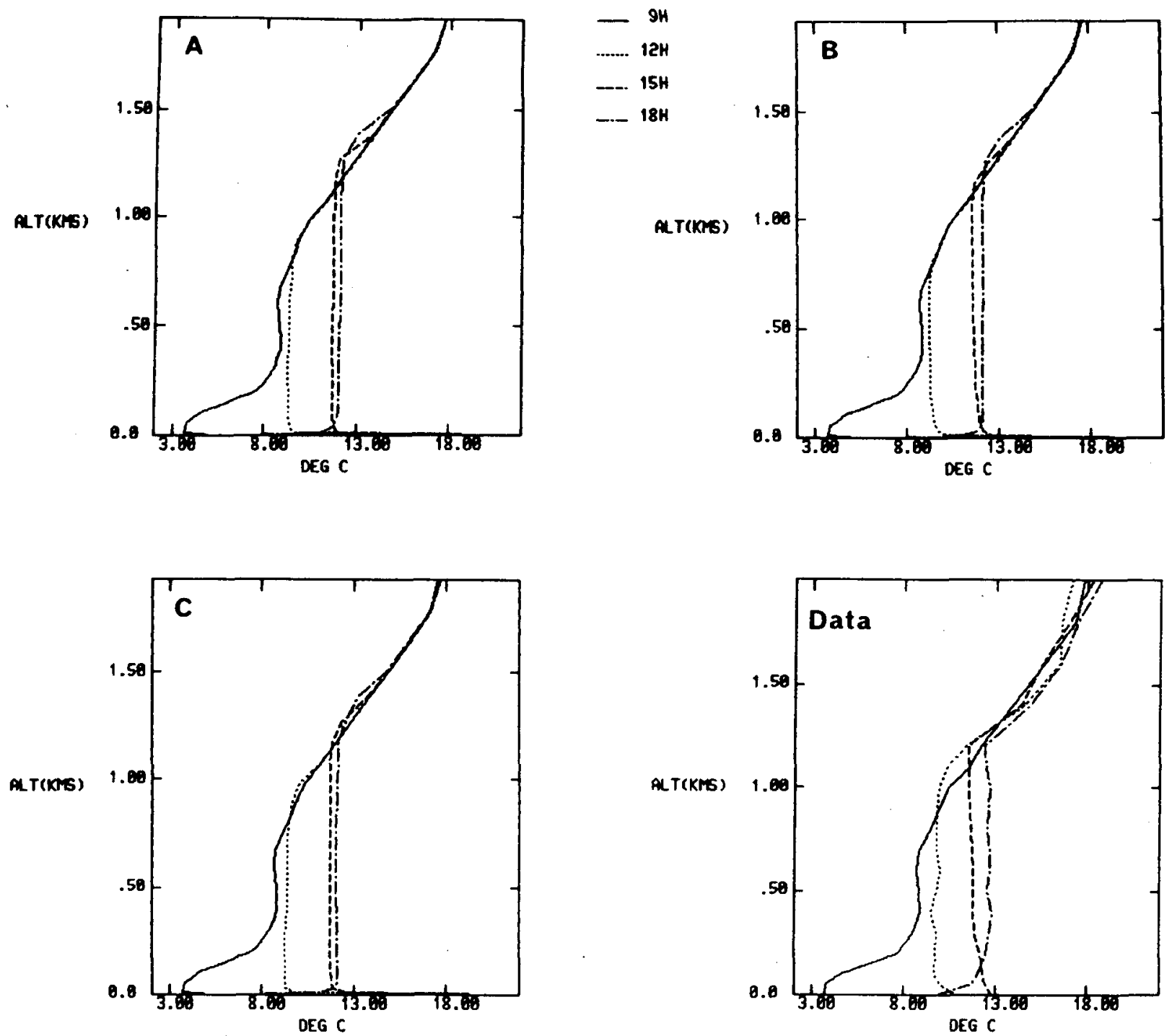

\section{Potential Temperature}

FiG. 2. Vertical profiles of the potential temperature $\left({ }^{\circ} \mathrm{C}\right.$ ) computed by models A, B, C and observed data at 0900 LST (solid lines), 1200 LST (dotted lines), 1500 LST (dashed lines) and 1800 LST (dot-dashed lines).

used in models A and B indicates that this latter difference results from the shape of the O'Brien polynomial used in model B. In the upper part of the mixed layer the O'Brien polynomial decreases smoothly from its maximum near $Z_{i} / 3$ to zero around the inversion level, whereas the exchange coefficient used in the Therry-Lacarrère model is nearly constant up to the top of the mixed layer and sharply vanishes above.

\section{f. Effect of the vertical resolution}

Up to this point, we have presented results obtained using 30 levels in the lowest $2.5 \mathrm{~km}$, while the threedimensional mesoscale model considered in section 3 makes use of a 15-level vertical grid, nine elements of which are located within the lowest $2.5 \mathrm{~km}$. The final experiment in this section, therefore, evaluates the effect of decreasing the vertical resolution on the accuracy of the TKE model predictions. A similar experiment has been conducted by Pielke and Mahrer (1975) with model $B$. With the 9-level coarser grid, the vertical resolution ranges from $17 \mathrm{~m}$ near the ground to 600 $\mathrm{m}$ at a height of $2 \mathrm{~km}$. The curves of time evolution of the PBL obtained for two 36-h simulations using exactly the same initial and surface conditions are shown in Fig. 6 for the 30-level grid (bottom diagram) and the 9-level grid (top diagram). The diurnal growth 


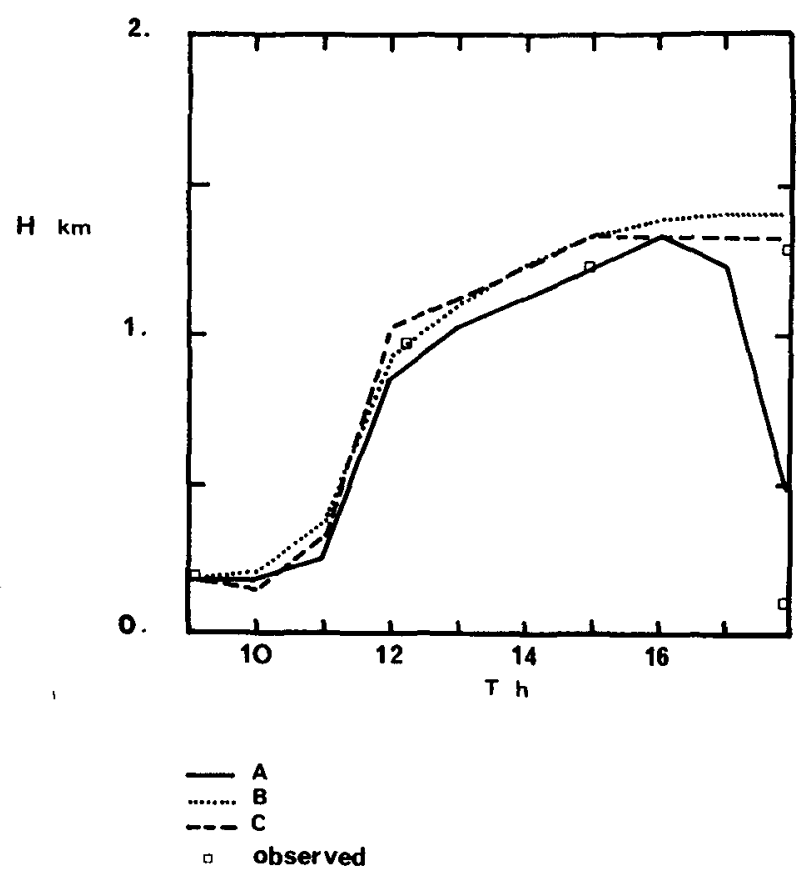

Fig. 3. Calculated depth of the mixed layer in models A (solid line), B (dotted line) and C (dashed line) and observed values (taken from Deardorff, 1974) denoted by open squares.

of the PBL is clearly smoother with the higher resolution grid, as the mixed layer depth is computed without interpolation between grid levels. However, a good agreement is obtained on the whole, with maximum values underestimated on the coarser grid by $120 \mathrm{~m}$ on the first day and by $240 \mathrm{~m}$ on the second day. At night, there is no difference between the two runs because the depth of the PBL is calculated as a function of the friction velocity when the PBL is stable. In Fig. 7 , the same comparison is made for the daytime profiles of the sensible heat flux. The agreement between the 9-level and the 30-level profiles is good, the nearly linear variation of the flux with height in the mixed layer being recovered in both simulations.

\section{g. Conclusion of the ID tests}

The conclusion of the tests presented in this section is therefore that the three techniques considered are able to simulate accurately the daytime evolution of the PBL over homogeneous surface conditions. For the PBL depth and temperature, the results of the three models are very similar. For the wind profiles, larger differences are found, the scatter between the solutions being 2-3 m s $\mathrm{m}^{-1}$, with slightly better results given by the TKE model. Another important point is that the behavior of the TKE model seems rather insensitive to decreasing the vertical resolution from 30 to 9 levels in the lowest $2.5 \mathrm{~km}$ of the troposphere.

\section{Comparison under horizontally inhomogeneous forcing}

In this section, a second set of comparisons is performed under horizontally inhomogeneous surface forcing using a 3D mesoscale model to simulate the sea breeze flow over south Florida. As suggested by the preliminary discussion in subsection $2 \mathrm{c}$, and following the conclusions of Anthes et al. (1980), the analysis of this type of flow would provide better insight into the TKE model's behavior, since sheared flow, surface heating and large-scale forcing are simultaneously acting.

However, as far as the description of the mesoscale structure of the turbulent variables over the Florida peninsula is concerned, very few experimental data are presently available. Moreover, most of these experimental studies are restricted to small domains, often near the southern edge of Lake Okeechobee (see Fig. 8 ). On the other hand, Pielke (1974) has made extensive numerical studies over Florida and performed a validation of his model using the existing empirical data (Pielke and Mahrer, 1978). Thus, our approach will be to use Pielke's results as a reference for the mean variables, and simultaneously compare qualitatively the turbulent structure with the detailed results of the thirdorder, turbulence closure two-dimensional (2D) sea breeze model of Brière (1987).

\section{a. Model description}

The three-dimensional numerical model is a dry version of the meso- $\beta$ model of Nickerson et al. (1986), which was originally developed to study flows over complex terrain. Since the equations have been discussed elsewhere in detail, only the main features and modifications are given herein.

The vertical coordinate $\nu$ is a stretched $\sigma$ pressure coordinate chosen to increase the vertical resolution in the PBL. Table 3 gives a comparison between the $\nu$ and $\sigma$ coordinates, together with the corresponding altitudes. The main change made to the original model discussed in Nickerson et al. (1986) is a simplification of the equations for moist thermodynamics, which do not include here the phase changes of water. This assumption was found adequate in most earlier studies of sea breezes. With this simplification, the thermodynamical and moisture equations, written for the variables $S=\Pi \theta$ and $W=\Pi q$, respectively, read,

$$
\begin{gathered}
\frac{\partial S}{\partial t}=-\frac{\partial}{\partial x}(u S)-\frac{\partial}{\partial y}(v S)-\frac{1}{\sigma^{\prime}} \frac{\partial}{\partial \nu}\left(\sigma^{\prime} \nu S\right)+F_{S}, \\
\frac{\partial W}{\partial t}=-\frac{\partial}{\partial x}(u W)-\frac{\partial}{\partial y}(v W)-\frac{1}{\sigma^{\prime}} \frac{\partial}{\partial \nu}\left(\sigma^{\prime} \nu W\right)+F_{W},
\end{gathered}
$$

where $\theta$ is the potential temperature, $q$ the water vapor mixing ratio, and $F_{S}$ and $F_{W}$ are eddy exchange terms discussed in subsection $3 \mathrm{~b}$. Symbols referred to are listed in the Appendix. 

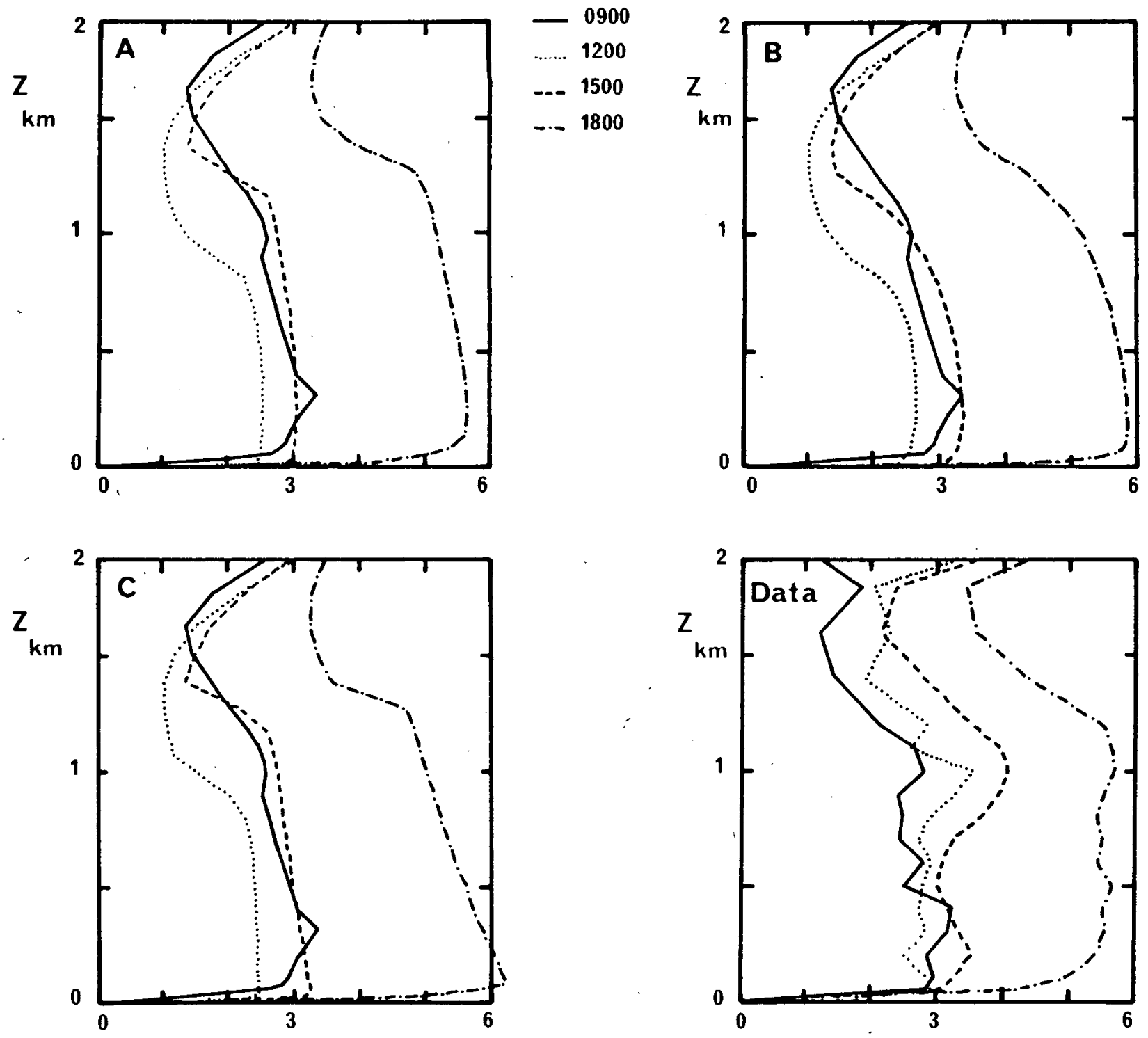

WIND $\mathrm{ms}^{-1}$

FIG. 4. Vertical profiles of the wind $\left(\mathrm{m} \mathrm{s}^{-1}\right)$ computed by models A, B, C and observed data at 0900 LST (solid lines), 1200 LST (dotted lines), 1500 LST (dashed lines) and 1800 LST (dot-dashed lines).

The surface layer fluxes of momentum, heat and moisture are based on the work of Businger (1973) using the formulation of Louis (1979).

The computational domain is the $24 \times 27$ central subdomain with constant mesh size used in Pielke's south Florida simulations. This domain is shown in Fig. 8. The uniform grid length is $11 \mathrm{~km}$ and the time step is $10 \mathrm{~s}$. At the lateral boundaries, radiation boundary conditions are used (Nickerson et al., 1986). The initial temperature, moisture and wind soundings are listed in Table 3, and the surface level conditions are given in Table 4. These surface and initial conditions are identical to those of Pielke (1974) and very similar to the ones for the south Florida simulation over dry sandy soil of Pielke and Mahrer (1978). A direct comparison is thereby possible with these previous studies.

\section{b. Turbulent flux parameterizations}

In order to test the effect of differences in PBL formulations on sea breeze circulations, a set of four simulations was performed where everything was identical 


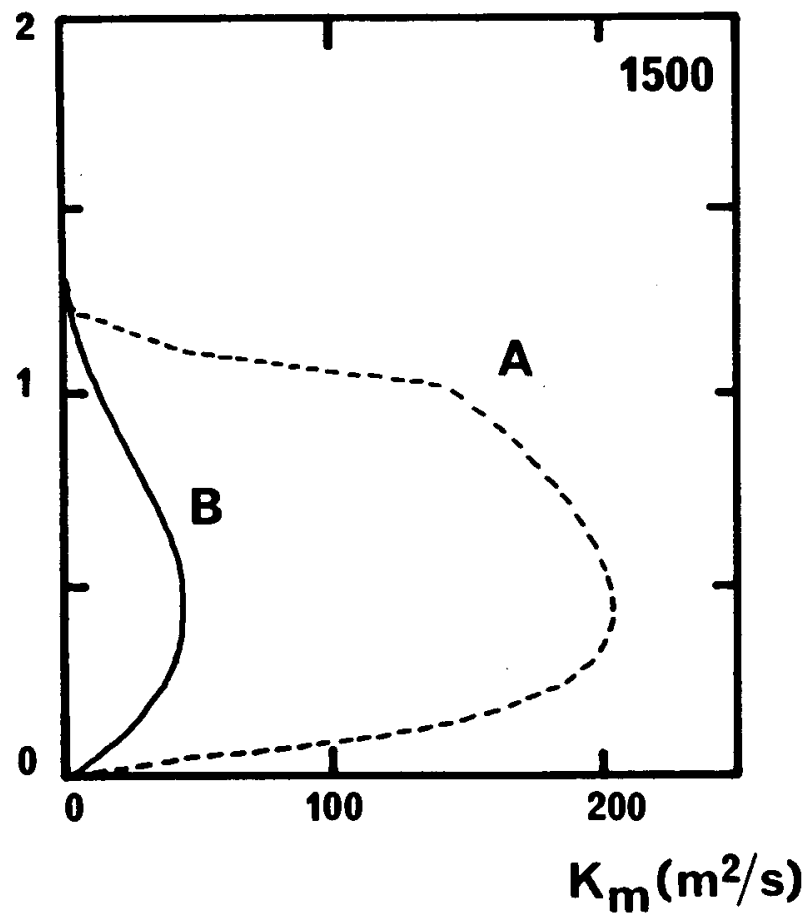

FIG. 5. Vertical profiles of the exchange coefficient $K_{M}\left(\mathrm{~m}^{2} \mathrm{~s}^{-1}\right)$ in models A (dashed line) and B (solid line) at 1500 LST.

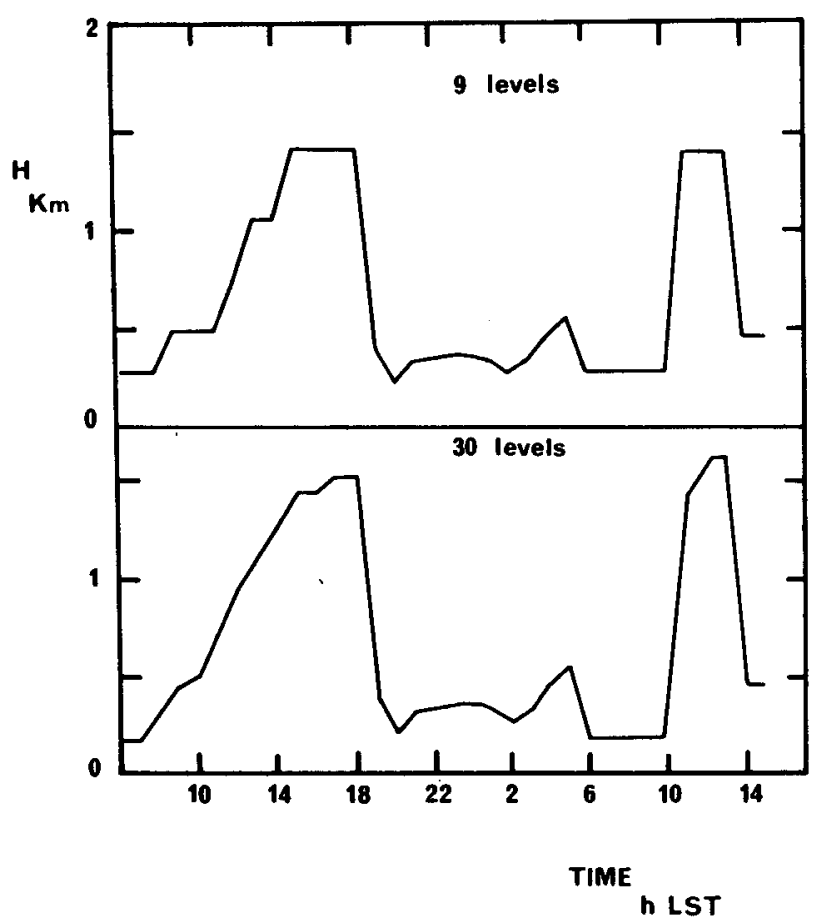

FIG. 6. Comparison of the time variations of the PBL depth $(\mathrm{km})$ predicted by the TKE model using different vertical grid resolutions. Upper portion: 9 levels; lower portion: 30 levels in the lowest 2.5 km.

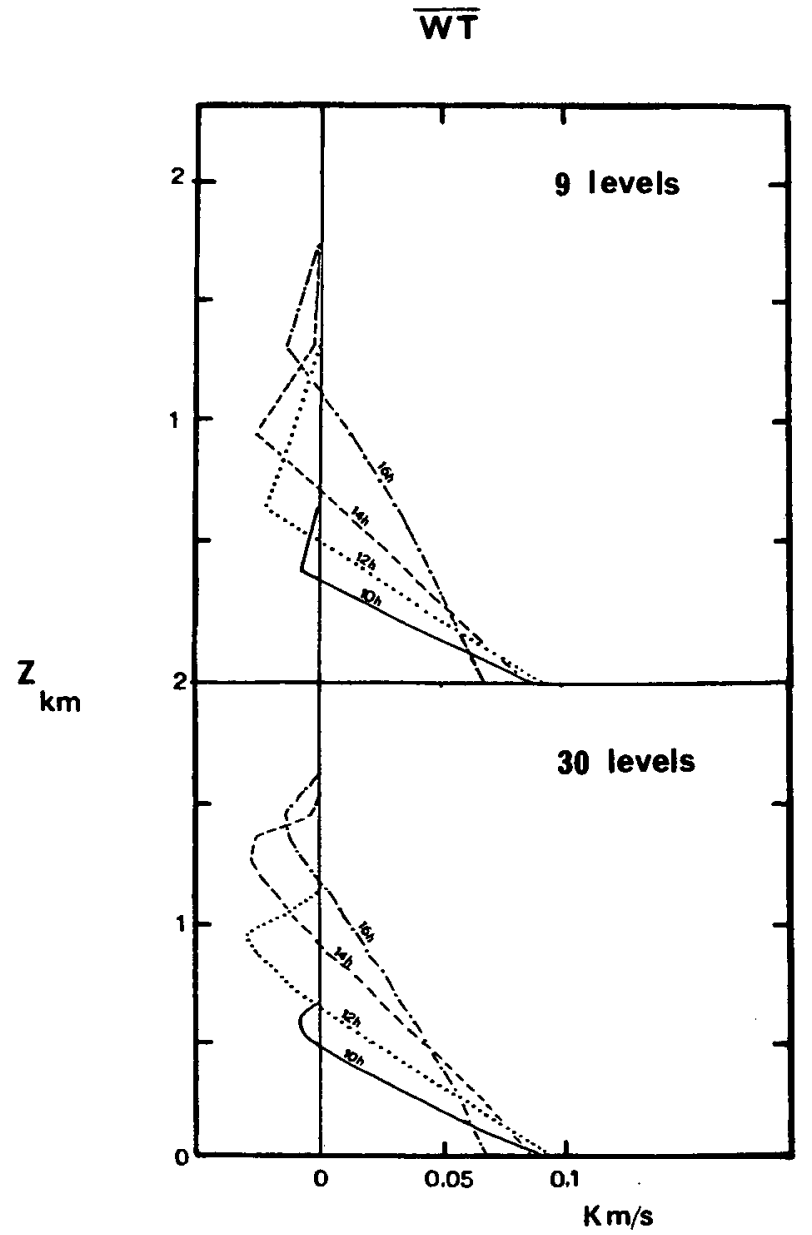

FIG. 7. Comparison of the time variations of the vertical profiles of heat flux $\left(\mathrm{K} \mathrm{m} \mathrm{s}^{-1}\right)$ predicted by the TKE model using different vertical grid resolutions. Upper portion: 9 levels; lower portion: 30 levels. Time given in LST.

except for the parameterizations of the turbulent fluxes. The first two simulations will receive most of the attention hereafter and were respectively made using the TKE parameterization (experiment A) and the Pielke and Mahrer (1975) parameterization (experiment B). Additionally, two other simulations of more technical interest were made using very simple schemes (experiments $\mathrm{D}$ and $\mathrm{E}$ ).

Implementation of the TKE parameterization in the three-dimensional model requires only few modifications to the original Therry-Lacarrère (1983) formulation given in subsection $2 \mathrm{~b}$. The turbulent fluxes are written in the $\nu$ coordinate system according to the following general expression:

$$
F_{\chi}=A \frac{\partial}{\partial \nu}\left(A K_{\chi} \frac{\partial \chi}{\partial \nu}\right)
$$




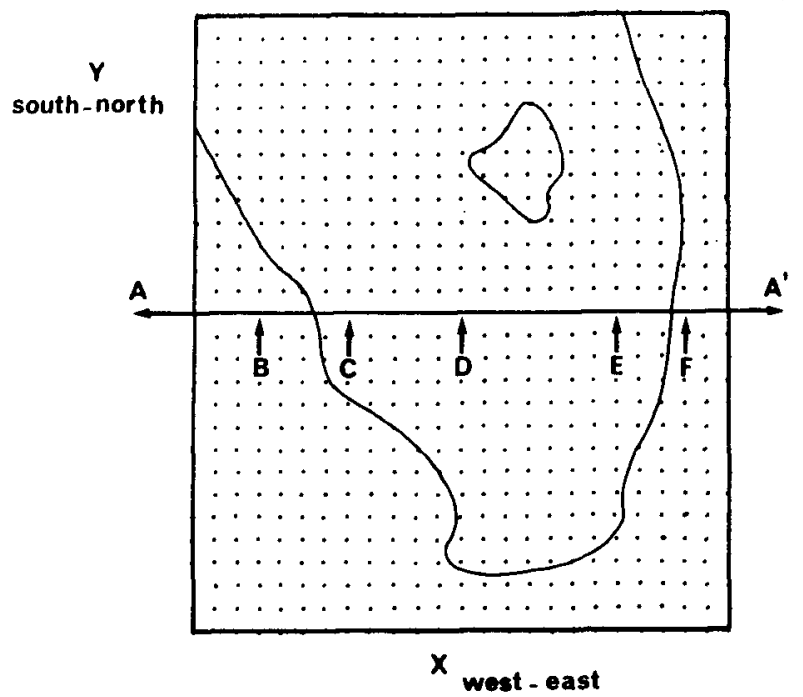

Fig. 8. Model grid for the 3D tests over south Florida. The smoothed coastline is taken from Pielke (1974). The line $\mathrm{AA}^{\prime}$ (along the 15 th west-east line) and points B-F are used for the cross-section analysis.

where $\chi$ is any arbitrary variable, $K_{x}$ the associated exchange coefficient and $A$ a scaling factor related to the $\nu$ system,

$$
A=-\frac{g p}{R T_{v} \Pi \sigma^{\prime}} .
$$

As explained in subsection $2 \mathrm{~b}$, the heat flux expression involves an additional countergradient term, namely,

$$
F_{S}=A \frac{\partial}{\partial \nu}\left[K_{H}\left(A \frac{\partial S}{\partial \nu}-\Pi \gamma_{c g}\right)\right]
$$

and the turbulent energy equation (9) is written as

$$
\begin{aligned}
\frac{\partial E}{\partial t}= & -\frac{\partial}{\partial x}(E u)-\frac{\partial}{\partial y}(E v)-\frac{1}{\sigma^{\prime}} \frac{\partial}{\partial \nu}\left(\sigma^{\prime} \nu E\right) \\
+ & A \frac{\partial}{\partial \nu}\left(1.3 A K_{M} \frac{\partial E}{\partial \nu}\right)+\Pi K_{M}\left[\left(A \frac{\partial u}{\partial \nu}\right)^{2}+\left(A \frac{\partial v}{\partial \nu}\right)^{2}\right] \\
& -\frac{\mathrm{g}}{\theta_{0}} K_{H}\left[\mathrm{~A} \frac{\partial \mathrm{S}_{v}}{\partial \nu}-\Pi \gamma_{c g}\right]-0.125 \Pi \frac{e^{3 / 2}}{l_{\varepsilon}},
\end{aligned}
$$

where $E=\Pi e$ and $S_{V}=\Pi \theta_{v}$. Other symbols are defined in the Appendix.

The second simulation has been made using formulation $B$ of subsection $2 \mathrm{~b}$. The turbulent fluxes are estimated using the vertical exchange coefficient of O'Brien, and the required depth $Z_{i}$ of the planetary boundary layer is computed from the prognostic equation of Deardorff (1974) used by Pielke and Mahrer (1975). Allowance is made for advective terms and vertical motion at level $Z_{i}$. At the lateral walls, the horizontal gradients of $Z_{i}$ are set equal to zero. Initial values of $Z_{i}$ are set equal to $200 \mathrm{~m}$.

In simulation $\mathrm{D}$, the PBL depth is evaluated diagnostically, $Z_{i}=0.25 u_{*} f^{-1}$, and the exchange coefficients of O'Brien are used, as before. Pielke and Mahrer (1975) found this scheme inaccurate; it is used here solely to allow a direct comparison with results of Pielke (1974) and trace back potential differences to their sources. In simulation $\mathrm{E}, Z_{i}$ is simply kept constant throughout the integration, with a value of $1 \mathrm{~km}$. This was the crude procedure formerly used in our model (Nickerson et al., 1986); an overall estimate of the im-

\begin{tabular}{|c|c|c|c|c|c|c|}
\hline$\nu$ & $\sigma$ & $Z(\mathrm{~m})$ & $T\left({ }^{\circ} \mathrm{C}\right)$ & $q\left(\mathrm{~g} \mathrm{~kg}^{-1}\right)$ & $u\left(\mathrm{~m} \mathrm{~s}^{-1}\right)$ & $v\left(\mathrm{~m} \mathrm{~s}^{-1}\right)$ \\
\hline 0.0333 & 0.0444 & 14816 & -44.7 & 0.0 & -4.2 & 4.2 \\
\hline 0.1000 & 0.1333 & 11752 & -44.7 & 0.0 & -4.2 & 4.2 \\
\hline 0.1667 & 0.2220 & 9604 & -31.0 & 0.0 & -4.2 & 4.2 \\
\hline 0.2333 & 0.3101 & 7891 & -19.8 & 0.0 & -4.2 & 4.2 \\
\hline 0.3000 & 0.3973 & 6464 & -10.5 & 0.0 & -4.2 & 4.2 \\
\hline 0.3667 & 0.4829 & 5244 & -2.6 & 1.5 & -4.2 & 4.2 \\
\hline 0.4333 & 0.5660 & 4191 & 3.1 & 3.6 & -4.2 & 4.2 \\
\hline 0.5000 & 0.6458 & 3277 & 7.2 & 5.4 & -4.2 & 4.2 \\
\hline 0.5667 & 0.7212 & 2488 & 11.1 & 7.1 & -4.2 & 4.2 \\
\hline 0.6333 & 0.7908 & 1810 & 14.8 & 9.0 & -4.2 & 4.2 \\
\hline 0.7000 & 0.8533 & 1238 & 18.3 & 11.3 & -4.2 & 4.2 \\
\hline 0.7667 & 0.9071 & 768 & 21.3 & 13.5 & -4.7 & 4.1 \\
\hline 0.8333 & 0.9504 & 404 & 23.6 & 15.7 & -4.7 & 3.6 \\
\hline 0.9000 & 0.9813 & 150 & 25.2 & 17.5 & -4.4 & 3.0 \\
\hline 0.9667 & 0.9978 & 17 & 26.2 & 18.0 & -2.9 & 1.8 \\
\hline 1.0000 & 1.0000 & 0 & 26.4 & 18.0 & 0.0 & 0.0 \\
\hline
\end{tabular}
provement obtained with respect to our original model is therefore provided by this simulation.

TABLE 3. Comparison of the $\nu$ and $\sigma$ coordinate systems to corresponding geometric altitudes, and initial conditions in the south Florida 3D simulations. Winds shown after Ekman adjustment for run E. 
TABLE 4. Surface level conditions and model parameters for the south Florida simulations.

\begin{tabular}{|c|c|c|}
\hline \multirow[b]{2}{*}{ Model parameter } & \multicolumn{2}{|c|}{ Value } \\
\hline & Over land & Over the sea \\
\hline $\begin{array}{l}\text { Roughness length } \\
\text { (cm) }\end{array}$ & 4 & $0.032 u_{*}^{2} g^{-1}$ \\
\hline $\begin{array}{l}\text { Surface level } \\
\text { temperature (K) }\end{array}$ & $\begin{array}{l}298+10 \sin \left(\pi^{t}\right. \\
(t \text { in LST })\end{array}$ & 298 \\
\hline $\begin{array}{l}\text { Surface level } \\
\text { moisture }\left(\mathrm{g} \mathrm{kg}^{-1}\right)\end{array}$ & 18 & 20,1 \\
\hline $\begin{array}{l}\text { Synoptic surface } \\
\text { pressure (mb) }\end{array}$ & & \\
\hline $\begin{array}{l}\text { Large-scale } \\
\text { geostrophic wind } \\
\left(\mathrm{m} \mathrm{s}^{-1}\right)\end{array}$ & & \\
\hline $\begin{array}{l}\text { Coriolis parameter } \\
\left(\mathrm{s}^{-1}\right)\end{array}$ & & \\
\hline $\begin{array}{l}\text { Model initialization } \\
\text { time (LST) }\end{array}$ & & \\
\hline
\end{tabular}

\section{c. Results obtained with the TKE parameterization}

We first consider the results from experiment $A$ which includes the TKE parameterization. The surface layer winds at $50 \mathrm{~m}$ and the vertical velocity fields at $1.2 \mathrm{~km}$ predicted at 3-h intervals from 0900 to 1800 LST are shown, respectively, in Figs. 9 and 10. The winds at $50 \mathrm{~m}$ were interpolated from the computed values at $150 \mathrm{~m}$ (level 14) and $17 \mathrm{~m}$ (level 15). The 1.2 $\mathrm{km}$ level is close to the maximum of the vertical motion field, as seen in Fig. 19A.

By $0900 \mathrm{LST}, 3 \mathrm{~h}$ after the beginning of the simulation (i.e., sunrise), the wind field (Fig. 9) is only slightly modified. The most noticeable perturbation is a weak divergence over Lake Okeechobee. The vertical motion field (Fig. 10) is much more organized, with upward cells around the eastern coast of the lake and along the west coast of the peninsula. These ascending cells are stronger where the curvature of the coast is convex, with maximum values for $w$ of about $2 \mathrm{~cm}$ $\mathrm{s}^{-1}$. By $1200 \mathrm{LST}$, the rotation of the winds (Fig. 9) is obvious on the west coast, and the sea breeze front has moved about $20 \mathrm{~km}$ inland. Over Lake Okeechobee, a well-defined divergent flow is seen, and a significant flow acceleration is predicted along the east coast over land. The vertical motion field (Fig. 10) is closely related to the horizontal wind convergence field, with the main line of ascending motion located along the west coast inland. The main subsidence areas are located over the sea along the west coast and over the western shore of the lake. By 1500 LST, the configurations of the horizontal and vertical wind fields are almost unchanged. Over the lake, the divergence of the winds (Fig. 9) begins to decrease, and vanishes later in the day. Along the west coast, the vertical motions (Fig.
10) are getting stronger. By 1800 LST, the penetration of the sea breeze front reaches about $50 \mathrm{~km}$ inland (Fig. 9), and the sea breeze circulations concentrate over the western half of the peninsula (Fig. 10). By the same time, the winds accelerate over the southeastern part of the peninsula and the main breeze cell along the western coast strengthens to a maximum vertical velocity of $21 \mathrm{~cm} \mathrm{~s}^{-1}$ (Fig. 10).

These features qualitatively agree in most respects with the results of Pielke although differences are found regarding the intensity and structure of the sea breeze front. We obtain a sharper front with maximum vertical velocities from about $11.8 \mathrm{~cm} \mathrm{~s}^{-1}$ at 1200 LST to about $22 \mathrm{~cm} \mathrm{~s}^{-1}$ at $1800 \mathrm{LST}$. By contrast, larger values were obtained in many previous studies: $50 \mathrm{~cm} \mathrm{~s}^{-1}$ at 1600 LST (Pielke, 1974), $25 \mathrm{~cm} \mathrm{~s}^{-1}$ at $1800 \mathrm{LST}$ with a nonhydrostatic model (Tapp and White, 1976), and $35 \mathrm{~cm} \mathrm{~s}^{-1}$ at 1800 LST (Pielke and Mahrer, 1978). A more detailed comparison with Fig. 5 of Pielke (1974) suggests that the onset of the sea breeze flow is more gradual in the present study since experiment A predicts a maximum velocity of only $1.8 \mathrm{~cm} \mathrm{~s}^{-1}$ at $0900 \mathrm{LST}$ whereas Pielke obtained values larger than $4 \mathrm{~cm} \mathrm{~s}^{-1}$ by that time. Another difference appears by comparing the wind fields predicted at 1500 LST, shown in Fig. 9, with Fig. 6 of Pielke (1974). In both simulations, the inland penetration of the sea breeze front is comparable, but the strongly divergent flow which forms downstream from Okeechobee Lake in Pielke's Fig. 6 does not appear in Fig. 11, which is more similar to Fig. 10 of Pielke and Mahrer (1978) or to Fig. 10 of Tapp and White (1976).

The vertical structure of the potential temperature field is illustrated in Fig. 11 where the vertical cross sections computed along the line AA' of Fig. 8 are presented at 3-h intervals. Early in the morning, a shallow mixed layer forms over land in response to ground heating, whereas nearly undisturbed stable layers are predicted over the sea along both coasts. By 0900 LST, this mixed layer is less than $1 \mathrm{~km}$ deep. It deepens to slightly more than $1 \mathrm{~km}$ by noon, reaching its maximum development of about $2 \mathrm{~km}$ after $1400 \mathrm{LST}$. Comparing Fig. 10 and Fig. 11, it can be seen that the depth of the mixed layer in Fig. 11 is related to the vertical velocity field, with a rise of the isentropes and a deeper mixed layer near the sea breeze front, within the main ascending cell of the breeze (e.g., see near 60 $\mathrm{km}$ in Fig. 10 at $1200 \mathrm{LST}$ ). The mixed layer also seems to be slightly shallower near both coasts where downward motions are predicted near the $1 \mathrm{~km}$ level. Later in the day, near sunset at 1800 LST in Fig. 11, the mixed layer is progressively destroyed, from the bottom, as a result of cold advection of marine air at low level at both coasts. This results in a horizontally inhomogeneous layer in the lowest kilometer, whereas a more homogeneous layer persists aloft. Similar transient features of the potential temperature field near 


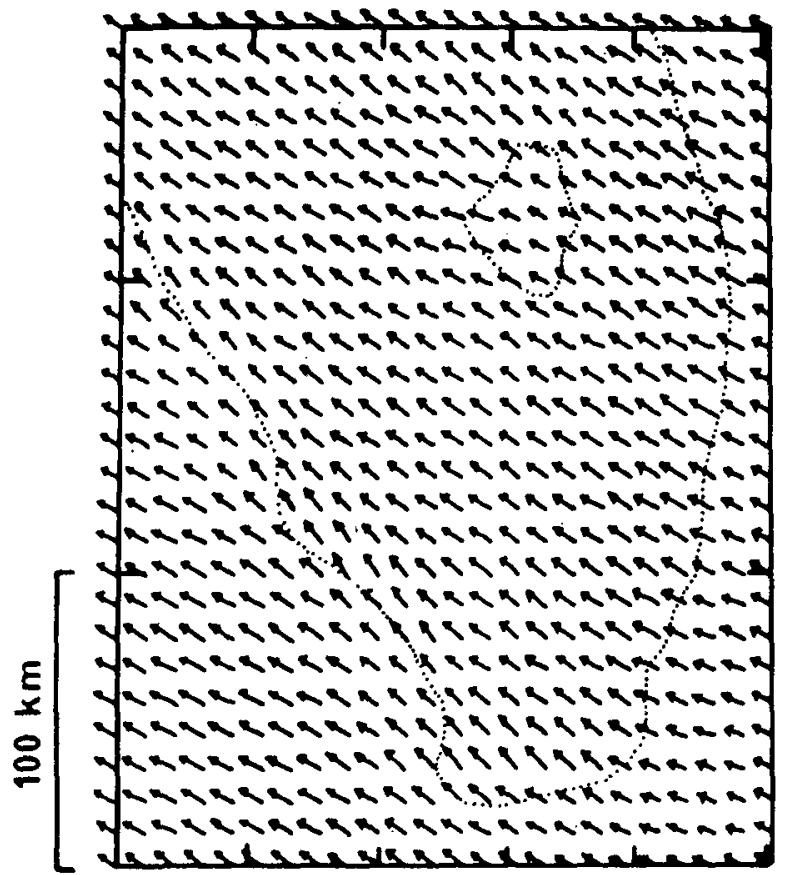

$50 \mathrm{~km}$

0900
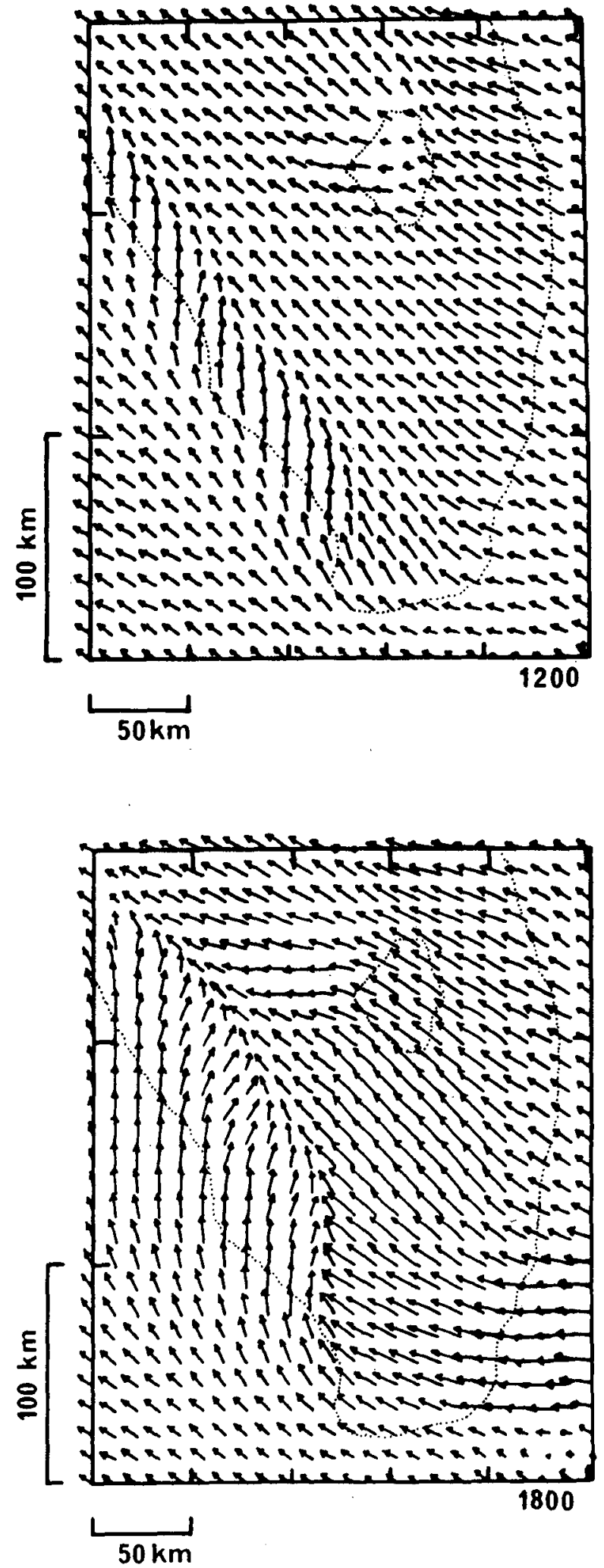

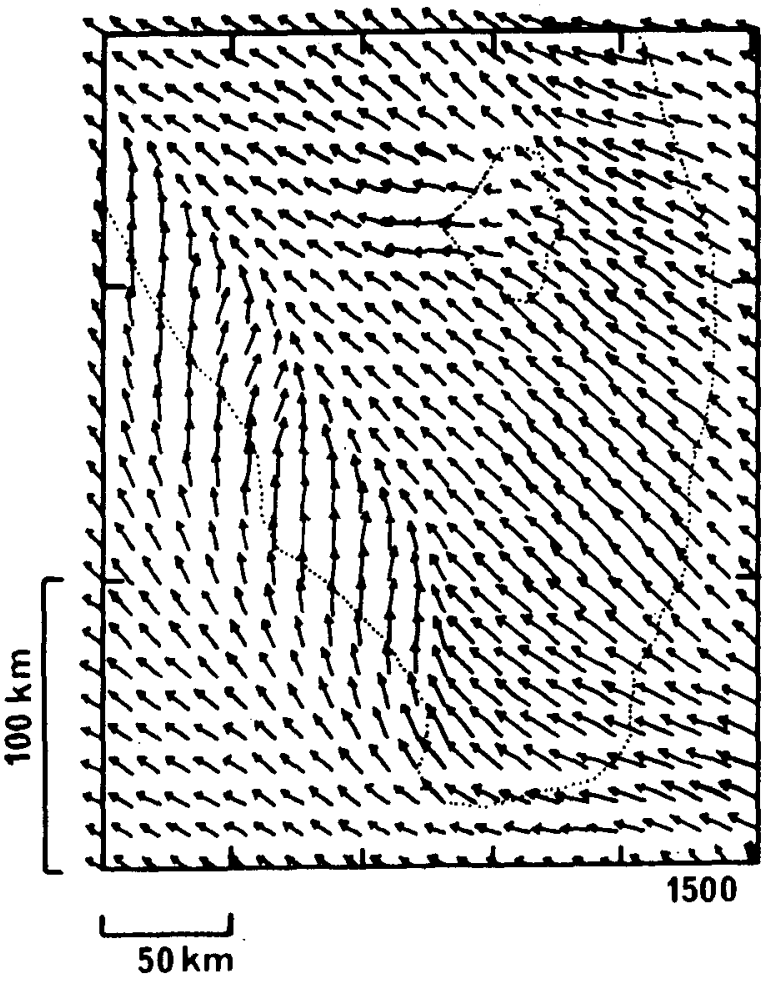



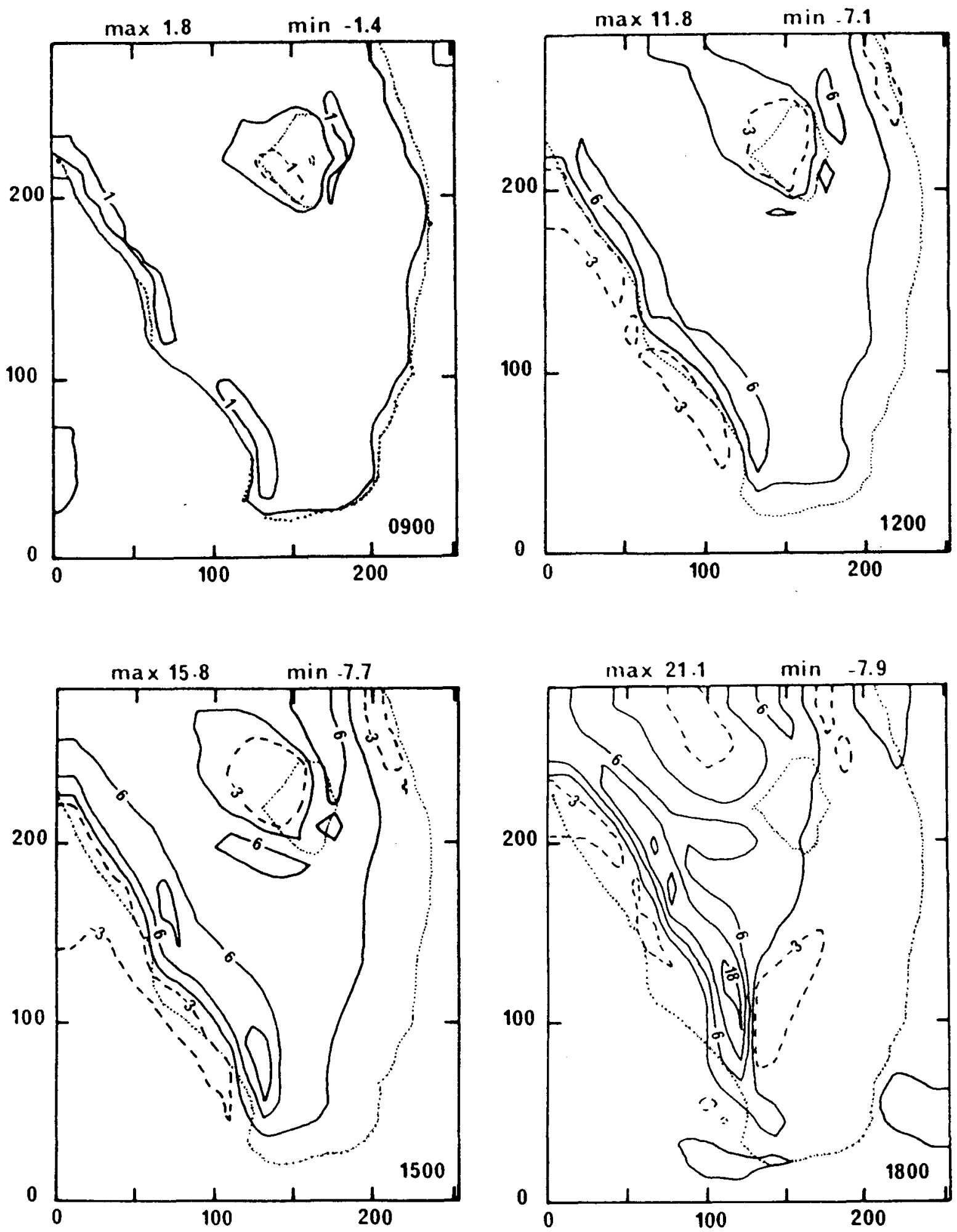

FIG. 10. Time evolution of the vertical velocity $\left(\mathrm{cm} \mathrm{s}^{-1}\right)$ at $1.2 \mathrm{~km}$ in experiment A (TKE parameterization). Contour interval is $6 \mathrm{~cm} \mathrm{~s}^{-1}$, except for the $-3 \mathrm{~cm} \mathrm{~s}^{-1}$ contour. All times are given in LST. The coastline is denoted by a dotted curve. Distances along ordinate and abscissa in $\mathrm{km}$. 

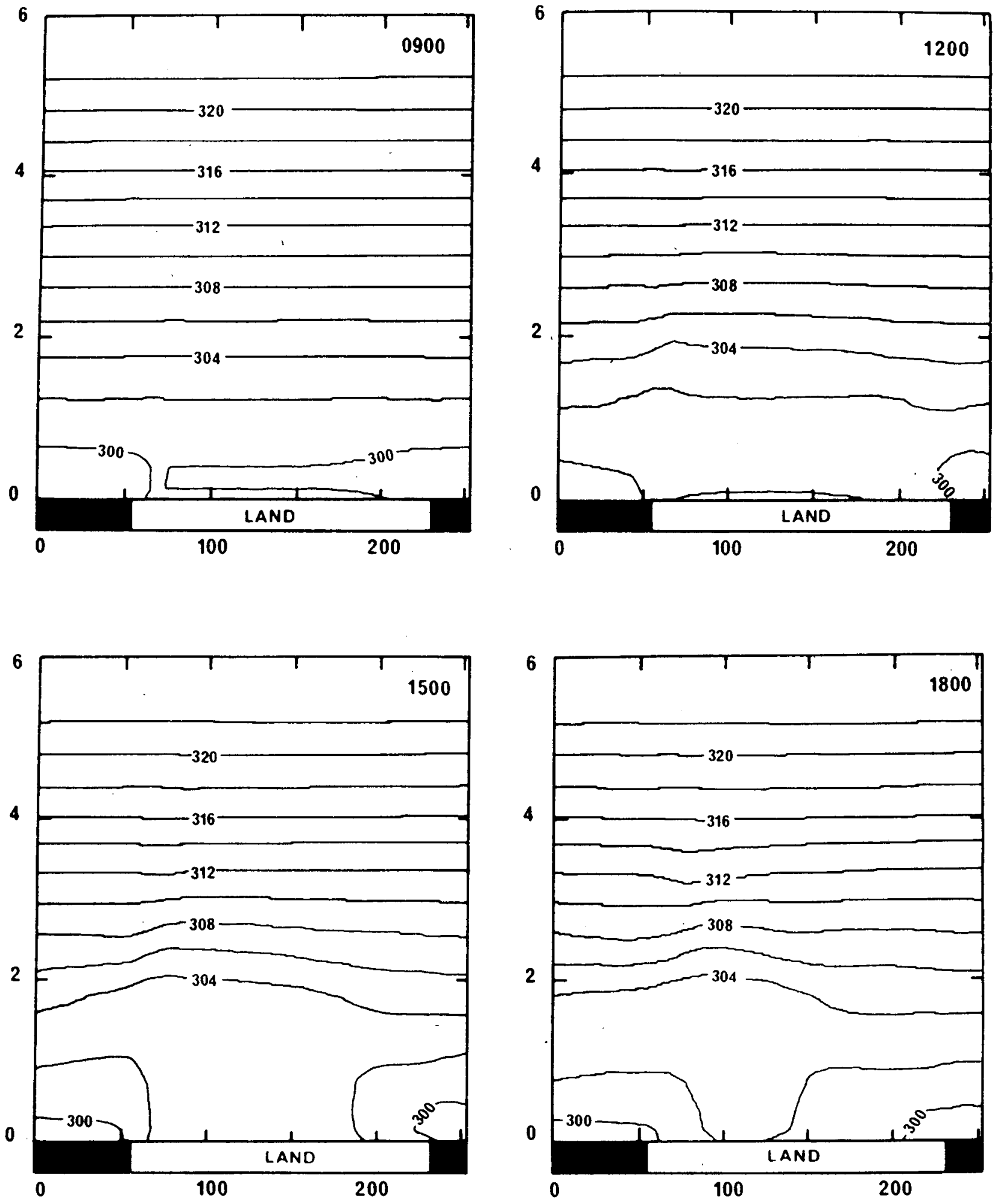

FIG. 11. Time evolution of the potential temperature $\left({ }^{\circ} \mathrm{C}\right)$ along the vertical cross section $\mathrm{AA}^{\prime}$ of Fig. 8 . Contours drawn at $2^{\circ}$ intervals. All times are given in LST. Vertical coordinate and abscissa in $\mathrm{km}$. 
sunset were obtained by Mizzi and Pielke (1984) in a simulation of sea breeze along the Oregon coast.

The structure of the predicted turbulence fields is now examined. Figures 12 and 13 respectively display at 1400 LST the vertical profiles of the sensible heat flux and of the turbulent energy at five selected locations ( $\mathrm{B}, \mathrm{C}, \mathrm{D}, \mathrm{E}$ and $\mathrm{F}$ ) along line $\mathrm{AA}^{\prime}$ in Fig. 8. At points $B$ and $F$, located over the sea near the western and eastern coasts of the peninsula, respectively, the surface layer is stably stratified and the turbulence is weak, leading to negligible turbulent energy and fluxes. At point $D$, located in the central part of the peninsula, the profiles of turbulent energy and heat flux are very similar to the profiles obtained in section $2 \mathrm{~d}$ over homogeneous terrain. The turbulent energy is larger than $1 \mathrm{~m}^{2} \mathrm{~s}^{-2}$ up to the $1 \mathrm{~km}$ level with a maximum greater than $2 \mathrm{~m}^{2} \mathrm{~s}^{-2}$ near $500 \mathrm{~m}$ (Fig. 13D). The heat flux profile exhibits the classical linear shape in the mixed layer with small negative values near the mixed layer top (Fig. 12D). More interesting features appear at locations C and E. By 1400 LST, point $C$ is located within the ascending cell associated with the sea breeze front along the western coast. The profile of the turbulent energy (Fig. 13C) shows a turbulent layer displaying a maximum of about the same value and at about the same level as at location D. However, this turbulent layer is much more active in the upper levels, with a turbulent energy roughly doubled in the second $\mathbf{k m}$. Similar features are observed in the heat flux profiles, with a ground level value equal to the flux at location $\mathrm{D}$ but larger values above $1 \mathrm{~km}$, and a mixed layer depth of about $2 \mathrm{~km}$. A significant departure of the heat flux profile from the linearity is also found, suggesting that, near the sea breeze front, the upward transport of heat is operated not only by the smallscale turbulence, but also by the mean vertical motion associated with the sea breeze circulation. Finally, the situation is quite different at point E. By $1400 \mathrm{LST}$, point $E$ is located within the eastern branch of the breeze flow where the surface southeast winds are accelerated and advect cold marine air. This region also displays a weak negative vertical velocity component aloft. The heat flux and energy profiles in Figs. 12E and $13 \mathrm{E}$ show a shallow mixed layer, with a surface heat flux nearly doubled with respect to points $D$ or $C$, and with nearly the same amount of turbulent energy. Thus, the advection of cold marine air at very low levels by the flow along the eastern coast of the peninsula strongly increases the instability of the surface layer.

As a last point in this section, we present cross sections taken along line $\mathrm{AA}^{\prime}$ of Fig. 8 for the turbulent kinetic energy and examine the four most significative terms of its budget. Figure 14 shows the turbulence energy field at 1430 LST along line $\mathrm{AA}^{\prime}$; this time roughly corresponds to the maximum development of the turbulence. Three regions with different character-

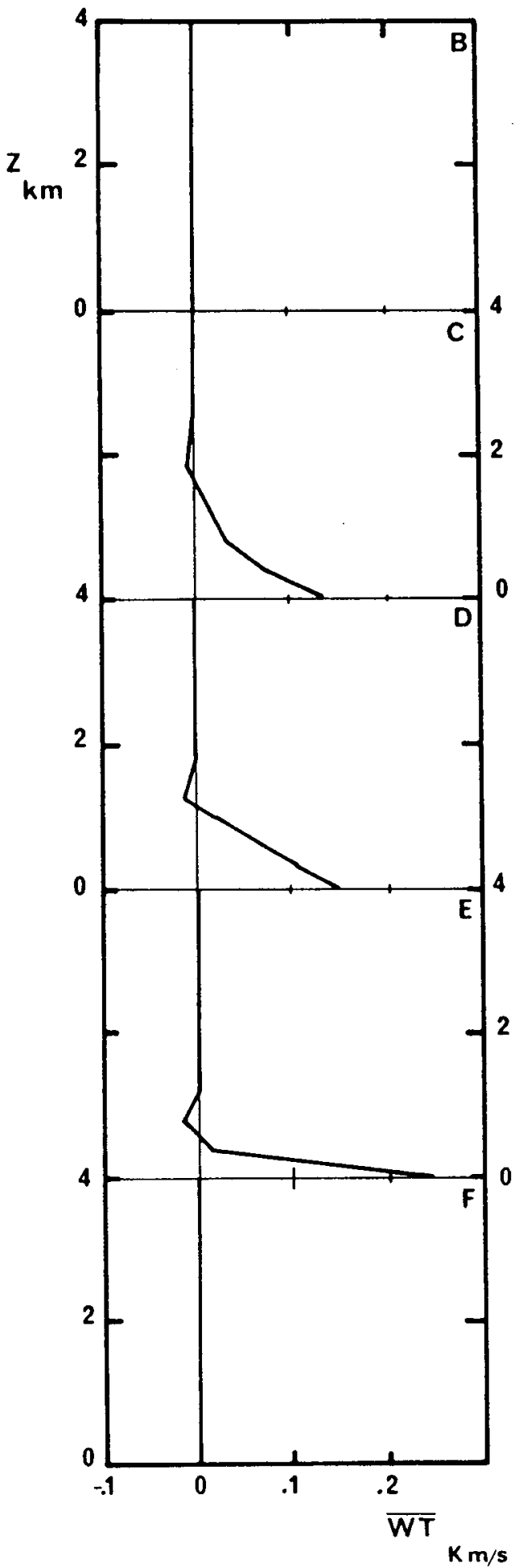

FIG. 12. Vertical profiles of the sensible heat flux $\left(\mathrm{K} \mathrm{m} \mathrm{s}^{-1}\right)$ at 1400 LST at five selected points along the line $\mathrm{AA}^{\prime}$ of Fig. 8. B, over the sea off the western coast; $C$, over land along western coast near the sea breeze front; D, central peninsula; E, over land, eastern coast; F, over the sea, eastern coast. 


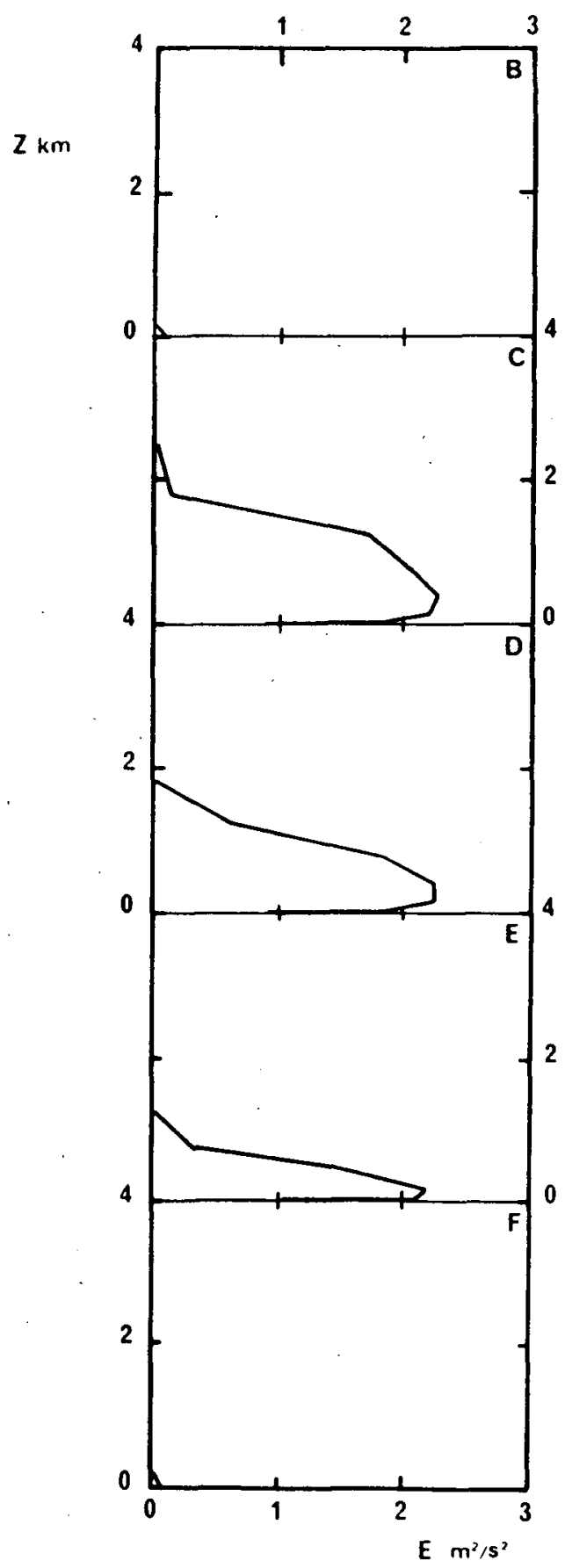

FiG. 13. As in Fig. 12 except for the turbulent kinetic energy $\left(\mathrm{m}^{2} \mathrm{~s}^{-2}\right)$ at $1400 \mathrm{LST}$.

istics are noticed. Over the sea, on both coasts, only negligible turbulence is predicted (as expected). Over land, sharp transitions occur along the shorelines between the nonturbulent and the turbulent regions. On both coasts, these transition regions broadly follow the surface separating the low-level branch of the breeze circulation from the overlying return current. The boundary is nearly vertical on the downwind side (west), more gently sloping on the upwind side (east). Near the center of the peninsula, the TKE is more homogeneous, with an average value of about $2 \mathrm{~m}^{2} \mathrm{~s}^{-2}$ at $500 \mathrm{~m}$ height, and exhibits a broad maximum of about $2.6 \mathrm{~m}^{2} \mathrm{~s}^{-2}$ and a deeper depth to the west near point $\mathrm{C}$, close to the main ascending cell of the breeze.

In order to interpret these features, we now examine the turbulent energy budget shown in Fig. 15 along the same cross section at the same time. Only the TKE shear production $\left.S=-\overline{\left(u^{\prime} w^{\prime}\right.} \partial u / \partial z+\overline{v^{\prime} w^{\prime}} \partial v / \partial z\right)$, the buoyancy production $B=g / \theta w^{\prime} \theta^{\prime}$, the turbulent transport $T=-\overline{\partial w^{\prime} e^{\prime}} / \partial z$, and the dissipation $D$ are presented; all other terms (including advection) are much smaller. It is seen that the turbulence is generated over land through buoyant production in the lower half of the convective layer, while the turbulent transport exports energy from the lower half to the upper half of the convective layer. The shear is small everywhere, except within the transition layers, where it can be larger than the buoyant production and significantly modifies the TKE, the turbulent transport and, to some extent, the dissipation. This last point emphasizes the necessity of allowing for wind shear turbulent production in sea breeze simulations.

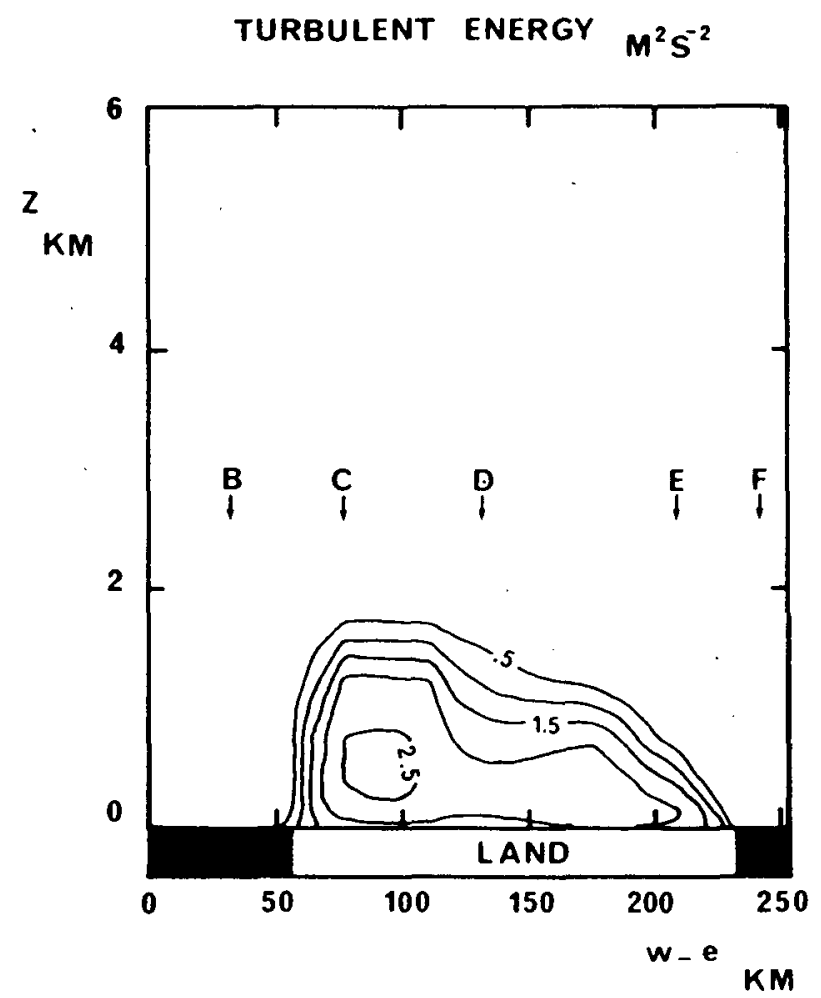

Fig. 14. Vertical cross section of the turbulent kinetic energy at 1430 LST along the line AA' of Fig. 8. Contours drawn at $0.5 \mathrm{~m}^{2} \mathrm{~s}^{-2}$ intervals. Maximum value is $2.6 \mathrm{~m}^{2} \mathrm{~s}^{-2}$. 


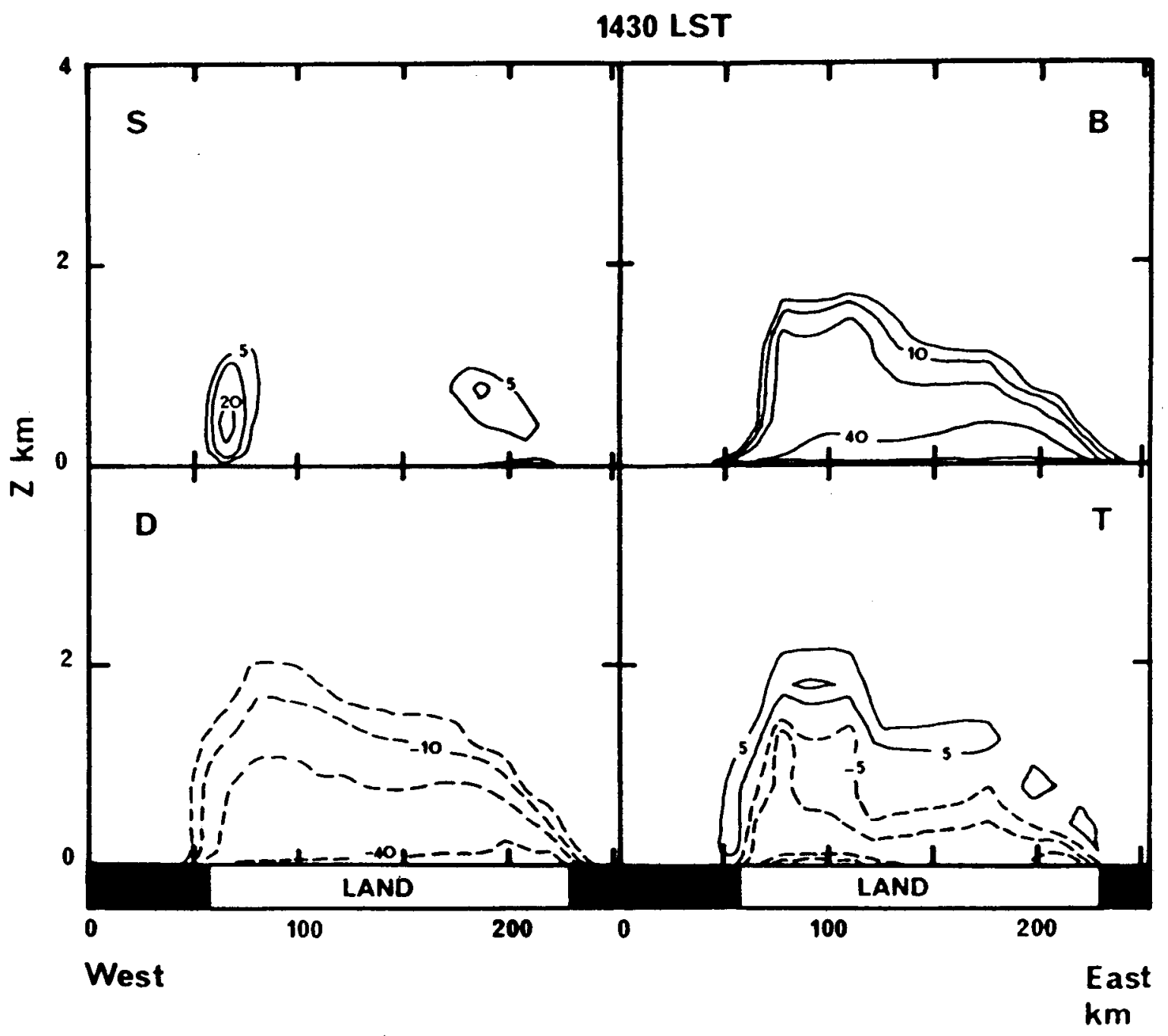

FIG. 15. Turbulent kinetic energy budget at 1430 LST; vertical cross section along the line AA' of Fig. 8. $S$, shear production; $B$, buoyant production; $T$, turbulent transport; $D$, dissipation. Units are $\mathrm{cm}^{2} \mathrm{~s}^{-3}$. Contours drawn for $\pm 5, \pm 10, \pm 20$ and \pm 40 $\mathrm{cm}^{2} \mathrm{~s}^{-3}$.

Brière (1987) has recently performed a two-dimensional sea breeze simulation with a very complex thirdorder turbulent closure which provides a detailed picture of the turbulent energy budget (along with many other second-order quantities). A qualitative comparison of our results is therefore attempted with this reference simulation. In spite of a coarser horizontal resolution (Brière, $2 \mathrm{~km}$ ) and a much more simplified physics in the present study, a reasonable agreement is obtained for the main contributions to the turbulent energy budget, as discussed later. For example, the shear production term computed in Brière's model exhibits a structure similar to the one we obtained, with a well-defined maximum within the transition region. Moreover, the predicted magnitudes agree in both models (Brière, $40 \mathrm{~cm}^{2} \mathrm{~s}^{-3}$, compared to $30 \mathrm{~cm}^{2} \mathrm{~s}^{-3}$ in this work). A similar consistency is found for the overall structure of the buoyancy production, with the exception of the very top of the mixed layer where the TKE scheme underestimates the negative flux (probably as a result of the poor vertical resolution at this elevation). Advective terms are also negligible in both simulations. More important differences are found, however, in the turbulent transport, which displays the same broad structure and magnitudes, but changes sign at much higher level in the TKE model than in Brière's. This defect can be ascribed to the gradient transport formulation used in (14). Therry and Lacarrère (1983) have mentioned this problem in their simulation and propose a refinement of (14) to cure it.

In summary, the analysis of the results of experiment A yields the following conclusions:

(i) The comparison with Brière (1987) third-order 
sea breeze model suggests that the TKE model gives a fair prediction of the turbulent structure at least for practical use.

(ii) The magnitude of the shear production in the transition regions near the sea breeze front shows a localized, but significant, interaction between the turbulence fields and the mesoscale mean flow.

(iii) The comparison of the mesoscale mean circulation with Pielke's results suggests that the sea breeze flow is weaker in the present simulation, a point to be discussed in subsection $\mathbf{3 d}$.

\section{d. Comparison of the TKE scheme with the other pa- rameterizations}

A more detailed discussion of the latter conclusion is now attempted using a comparison between the fields predicted at 1200 LST in experiments A, B, D and E. The surface layer winds at $50 \mathrm{~m}$ predicted in the four experiments are shown in Fig. 16. We first note that, in spite of the large differences in the PBL parameterizations, the predicted winds are very similar. Only minor differences are seen along the sea breeze front and over the lake, where the flow appears slightly more divergent in experiments $\mathrm{D}$ and $\mathrm{E}$, in agreement with the results of Pielke (1974). The vertical cross sections of the potential temperature fields at 1200 LST are shown in Fig. 17 for the four experiments. These fields are similar and show a mixed layer forming over land and stably stratified layers over the sea along both coasts. Close to the sea breeze front, along the western coast, some lifting of the isentropes is noticed in all experiments. By 1200 LST, the four experiments predict nearly the same PBL thermal structure and depth, but this is not significant in experiment $E$ because a comparison made at a later time in the day with this experiment would show an unstable layer between 1 and $2 \mathrm{~km}$, due to the use of an underestimated PBL depth. The vertical motion fields at 1200 LST are presented in the form of horizontal cross sections at the $1.2 \mathrm{~km}$ level in Fig. 18 and vertical cross sections along the line $\mathrm{AA}^{\prime}$ in Fig. 19. The same features are present in all four simulations, with regions of ascending motion confined along the western coast and upstream from the lake. Weak subsidences are found slightly inland over the east coast, off the west coast and downstream from the lake. However, substantial differences in flow strength are found between these four experiments. The regions of maximum ascent are weaker in experiments $A$ and $B$ than in experiments $D$ and $E$, which use crude diagnostic schemes. This difference reaches a factor of $2\left(10 \mathrm{~cm} \mathrm{~s}^{-1}\right)$ between experiments $B$ and $D$ in both the vertical and horizontal cross sections. By contrast, the maximum strength of the subsidences is almost the same for all the experiments, the differences being always smaller than $2 \mathrm{~cm} \mathrm{~s}^{-1}$.

In a quantitative study of sea breeze circulations, Anthes (1978) has shown that the daytime circulation results as a first approximation from an equilibrium between the solenoid acceleration and the counteracting effect of the vertical turbulent mixing of momentum. Consequently, we have compared the mixed layer characteristics in the four experiments in an attempt to explain the weaker circulation found with A and B parameterizations. The most noticeable difference found is that the PBL along the western coast is significantly deeper in experiments $A$ and $B$ than in experiments $\mathrm{D}$ and $\mathrm{E}$. This point is illustrated in Fig. 20 which shows the cross section of the mixed layer depth predicted at $1200 \mathrm{LST}$ along the line $\mathrm{AA}^{\prime}$ in experiments A, B and D. The mean depths of the PBL are similar in experiments $A$ and $B$ (accurate experimental data are lacking) and about $30 \%$ smaller in experiment D. In this latter case, the mixed layer depth is proportional to the friction velocity alone, which is a maximum along the east coast in the region where surface winds are accelerated. By contrast, in experiments A and $B$, the mixed layer depth responds both to the surface sensible heat flux and to the vertical velocity field in the PBL. The vertical velocity is maximum along the sea breeze front, whereas the surface heat flux is maximum along the east coast in response to the accelerated winds in this area. By 1200 LST, this results in a nearly constant (experiment A) or slightly deeper mixed layer to the west (experiment B). By 1430 LST, the turbulent energy reaches its maximum intensity and both models $A$ and $B$ give a deeper mixed layer to the west, whereas model $\mathrm{D}$ gives the opposite result, as also seen in Fig. 21. The above discussion therefore suggests that the less intense sea breeze circulations predicted with models A and B result from the deeper turbulent vertical mixing near the ascending cell of the flow.

\section{Summary and conclusions}

In this paper, various PBL parameterizations currently used in 3D mesoscale models were compared with the TKE parameterization of Therry-Lacarrère (1983). Two sets of sensitivity experiments were performed, corresponding to different physical conditions.

The first set of experiments was made under horizontally homogeneous ground forcing using the classical observational data of Wangara day 33. The TKE parameterization predicted values of the winds, temperatures and soil temperatures in good agreement with the observations, and the comparison made with the schemes of Zhang and Anthes (1982) and Pielke and Mahrer (1975) showed a slight improvement of the simulated wind profiles with the TKE scheme. It was also shown that the behavior of the Therry-Lacarrère TKE parameterization is rather insensitive to the effect of decreasing the vertical resolution from 30 to 9 levels in the lowest $2.5 \mathrm{~km}$ of the troposphere.

The second set of experiments was made under hor- 
A

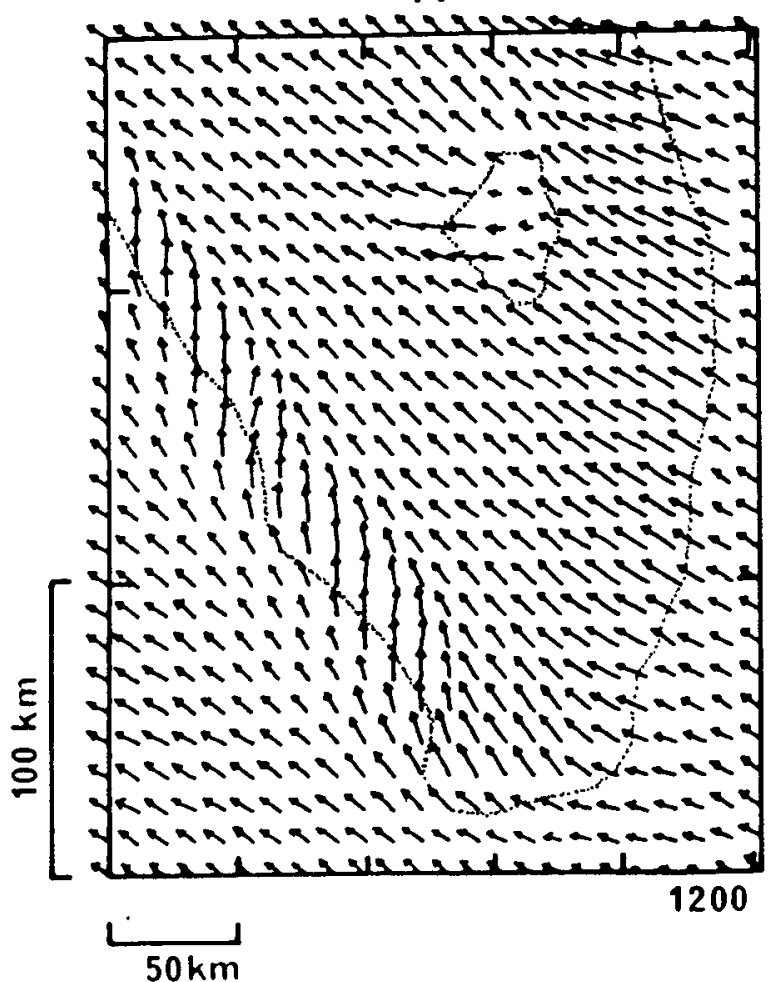

D

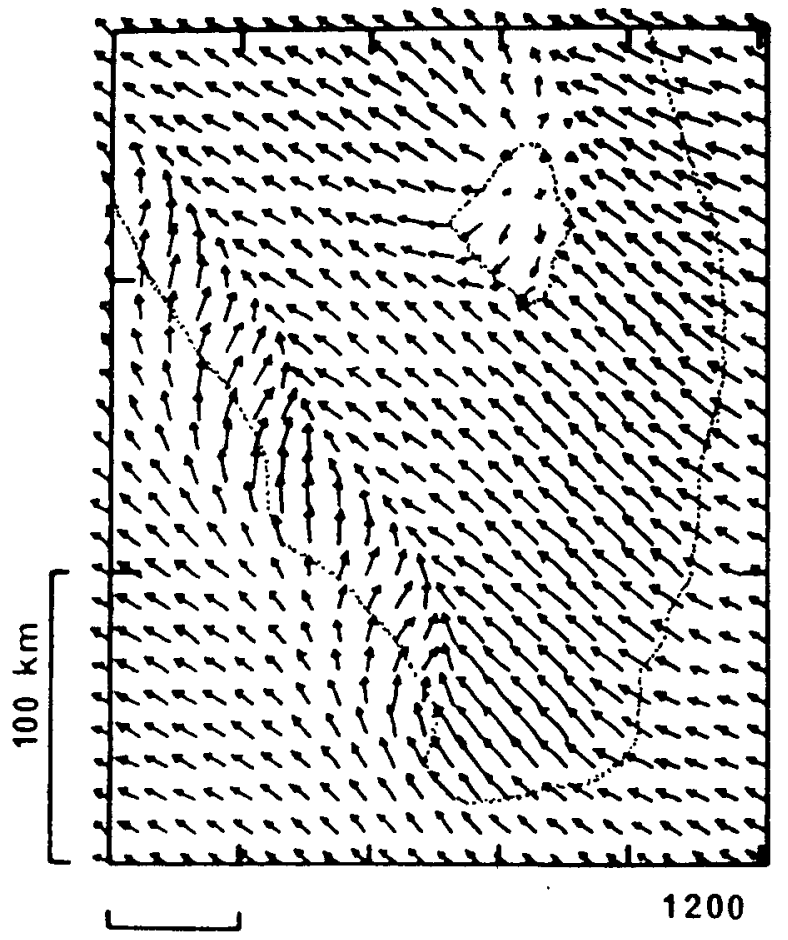

$50 \mathrm{~km}$

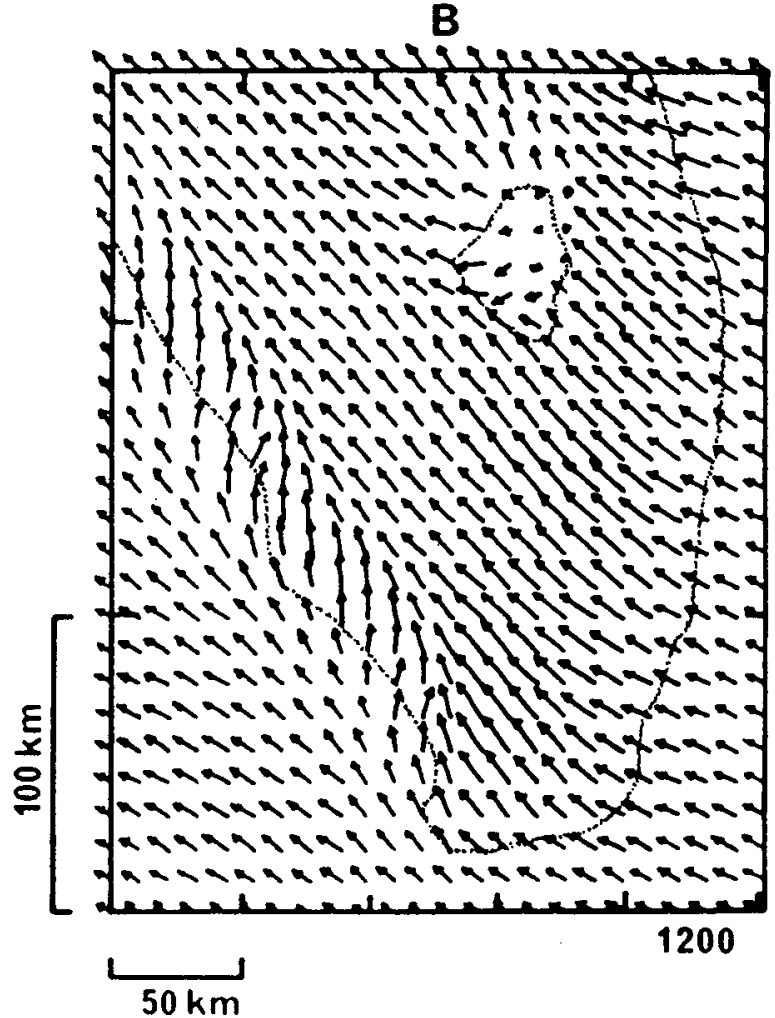

E

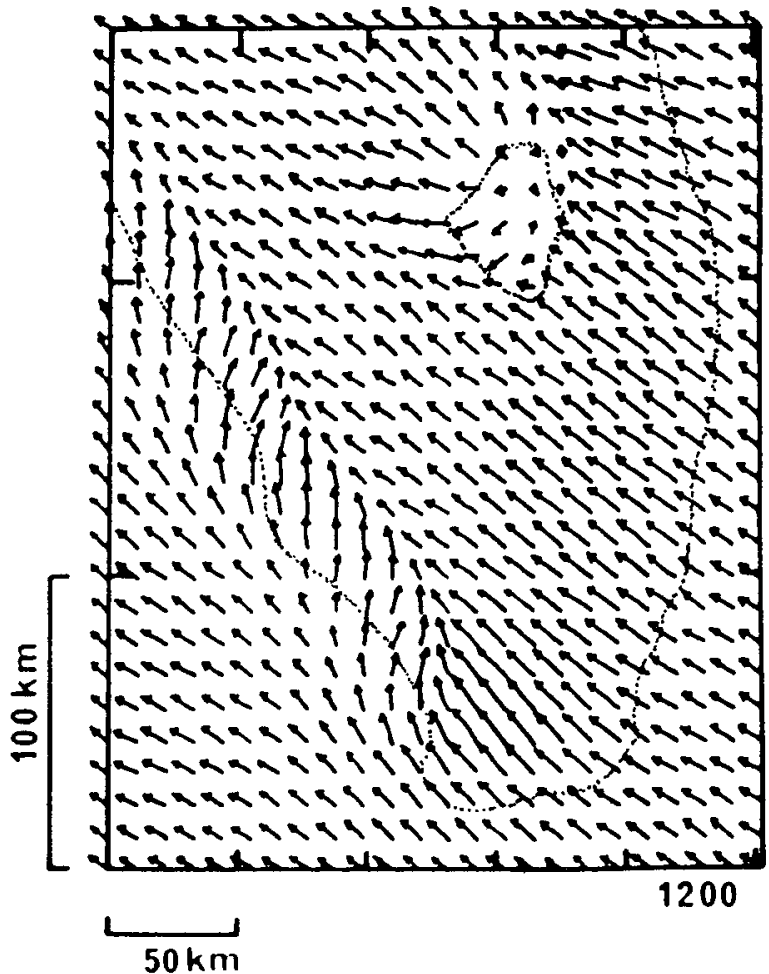

FIG. 16. Comparison of the surface layer winds at $50 \mathrm{~m}$ predicted at $1200 \mathrm{LST}$ : experiment A, TKE prognostic scheme; experiment B, Pielke and Mahrer (1975) scheme; experiment D, Pielke (1974) diagnostic scheme; and experiment E, constant PBL depth. The distance between two marks corresponds to a $5 \mathrm{~m} \mathrm{~s}^{-1}$ wind. 
A

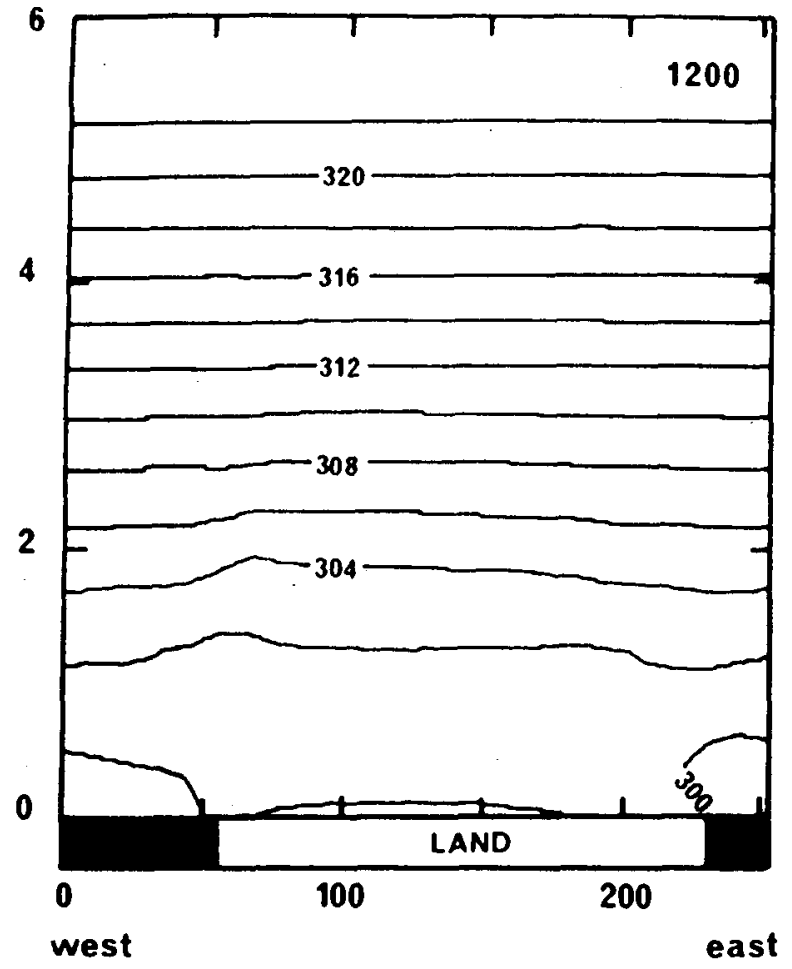

B

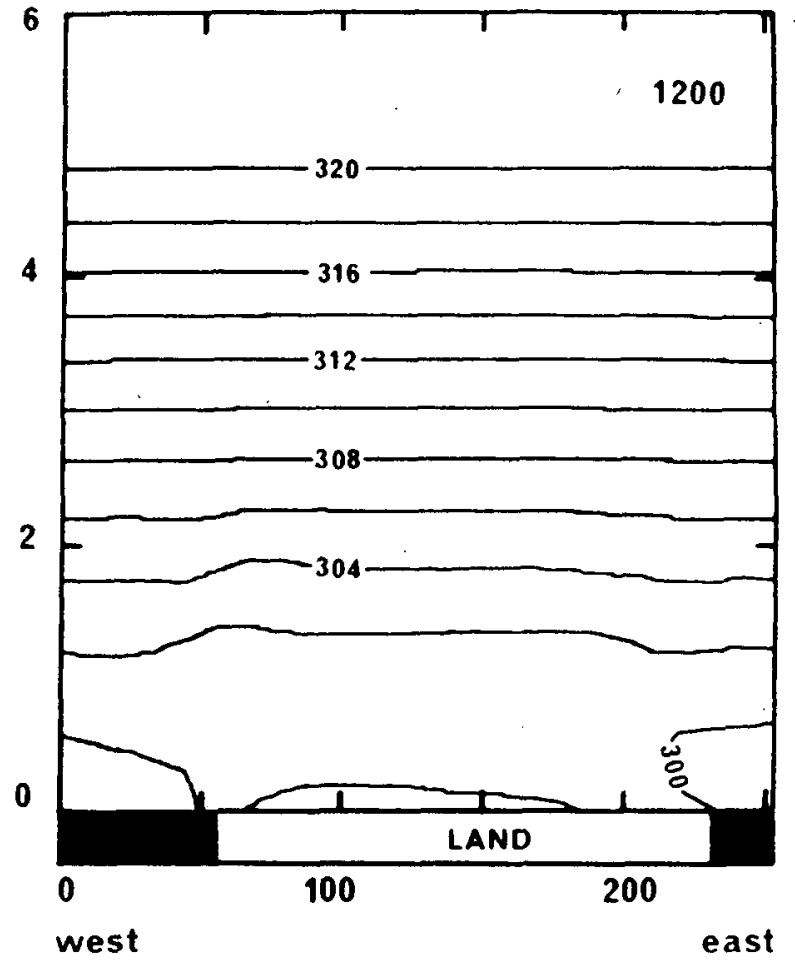

D

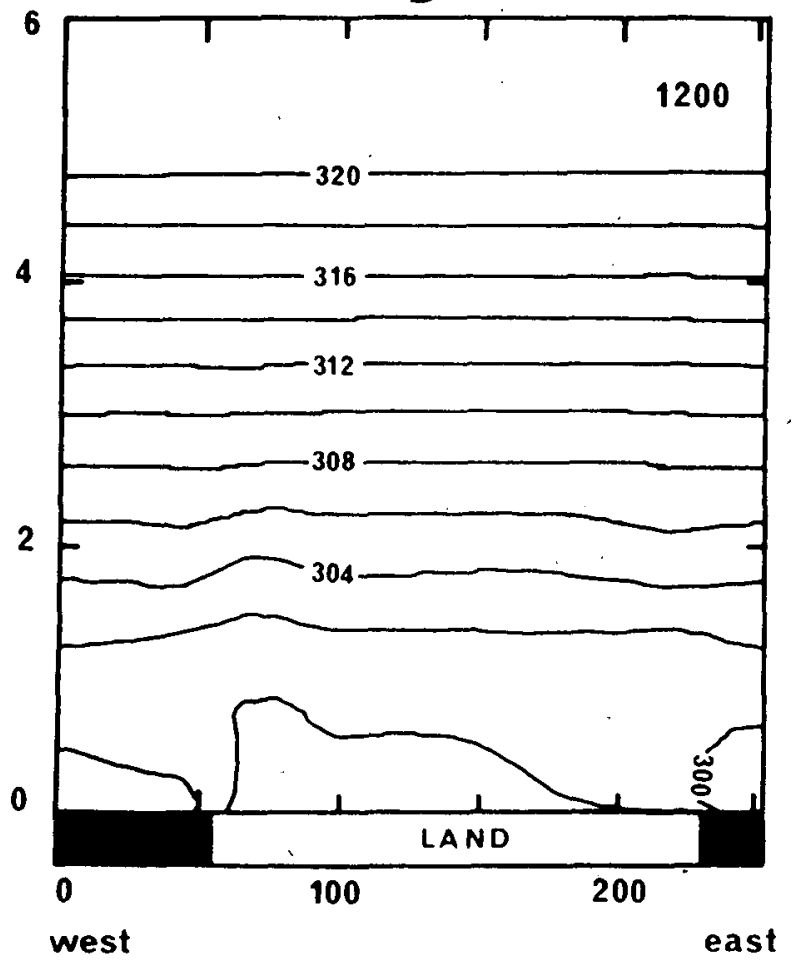

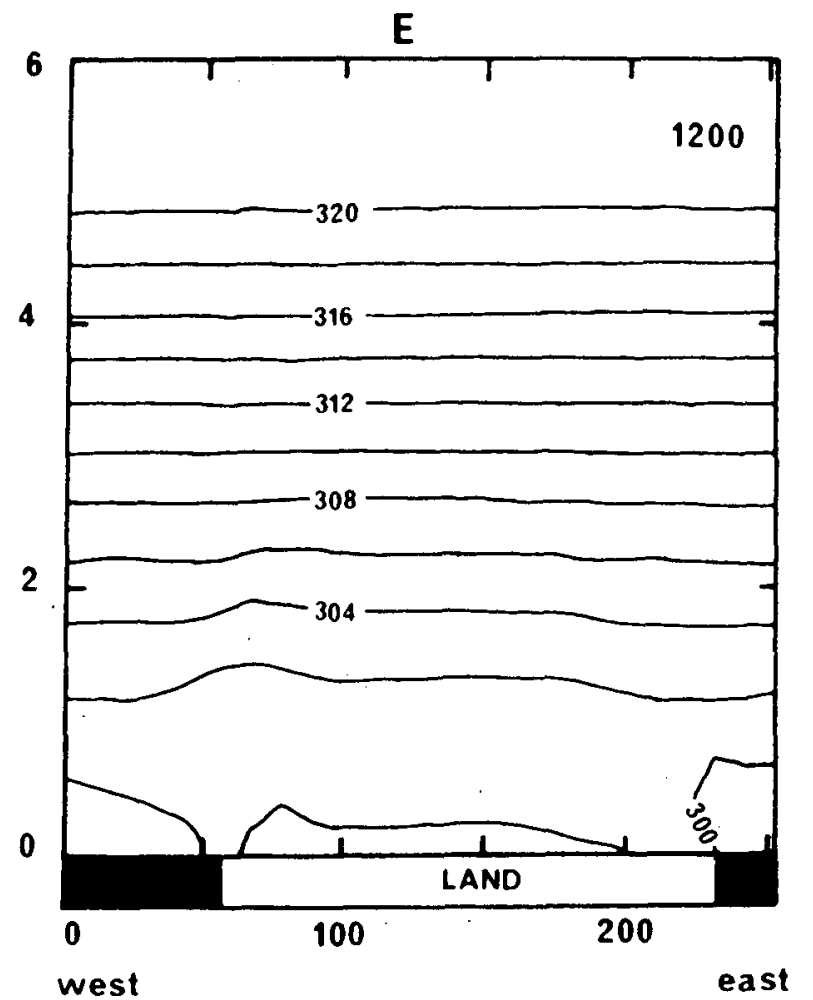

FiG. 17. Comparison of the potential temperature $\left({ }^{\circ} \mathrm{C}\right)$ at $1200 \mathrm{LST}$ along the vertical cross section AA' of Fig. 8. Contours drawn at $2^{\circ}$ intervals. Experiment A, TKE prognostic scheme; experiment B, Pielke and Mahrer (1975) scheme; experiment D, Pielke (1974) diagnostic scheme; experiment E, constant PBL depth. Vertical coordinate and abscissa in $\mathrm{km}$. 

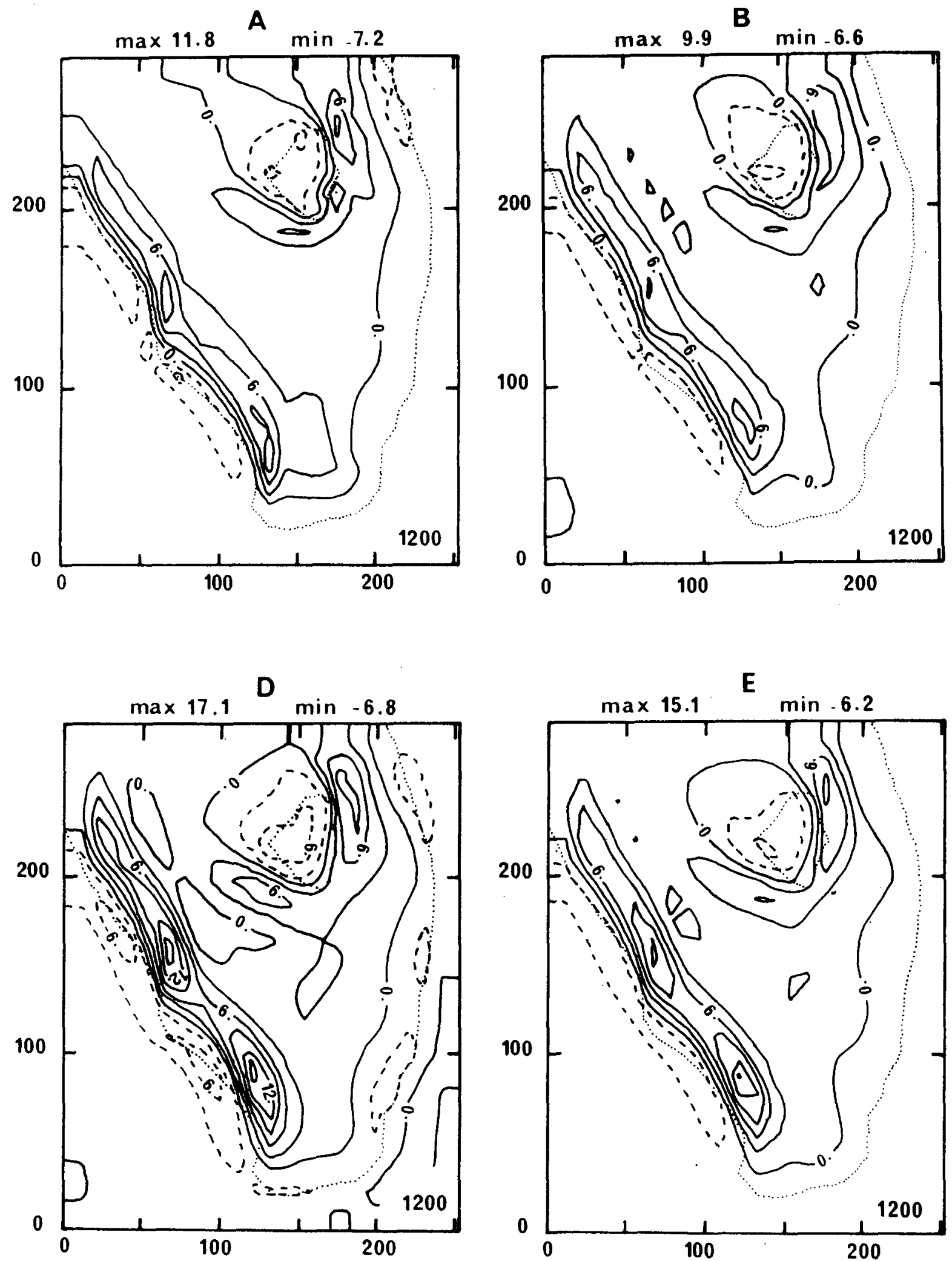

FIG. 18. As in Fig. 16 except for vertical velocity $\left(\mathrm{cm} \mathrm{s}^{-1}\right)$ at 1200 LST. 
A
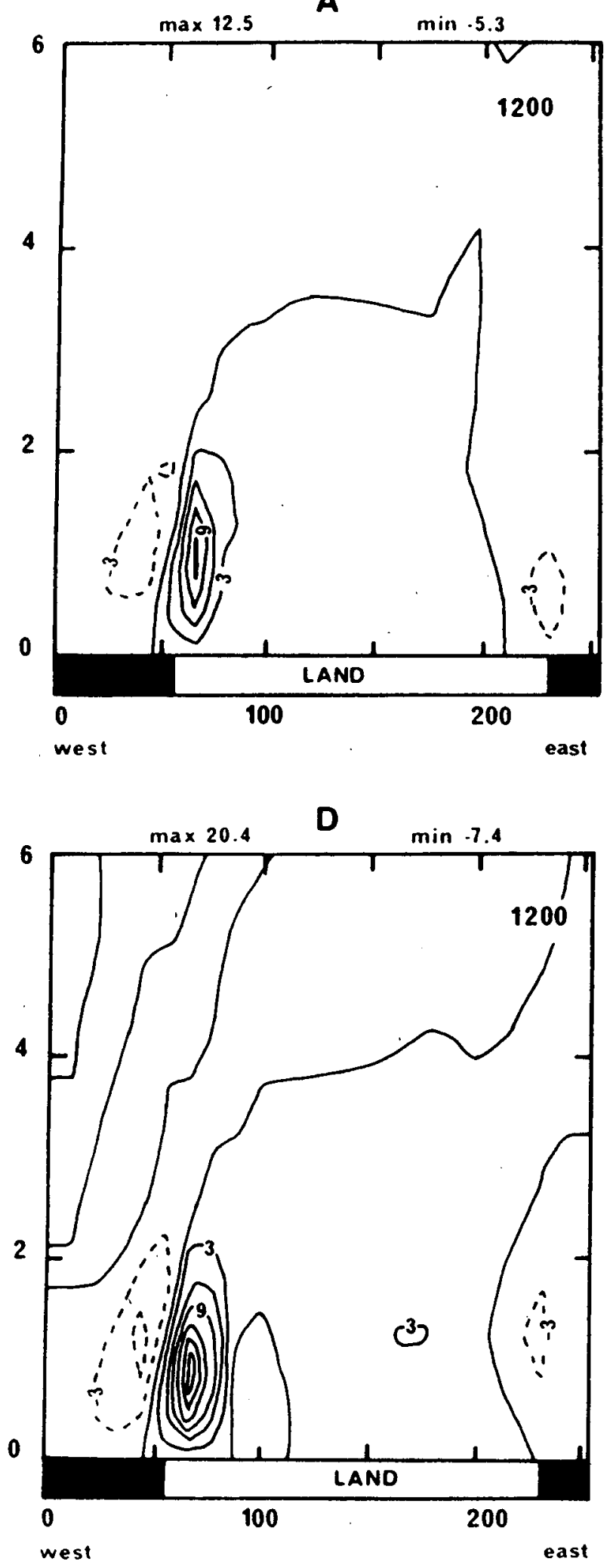

0
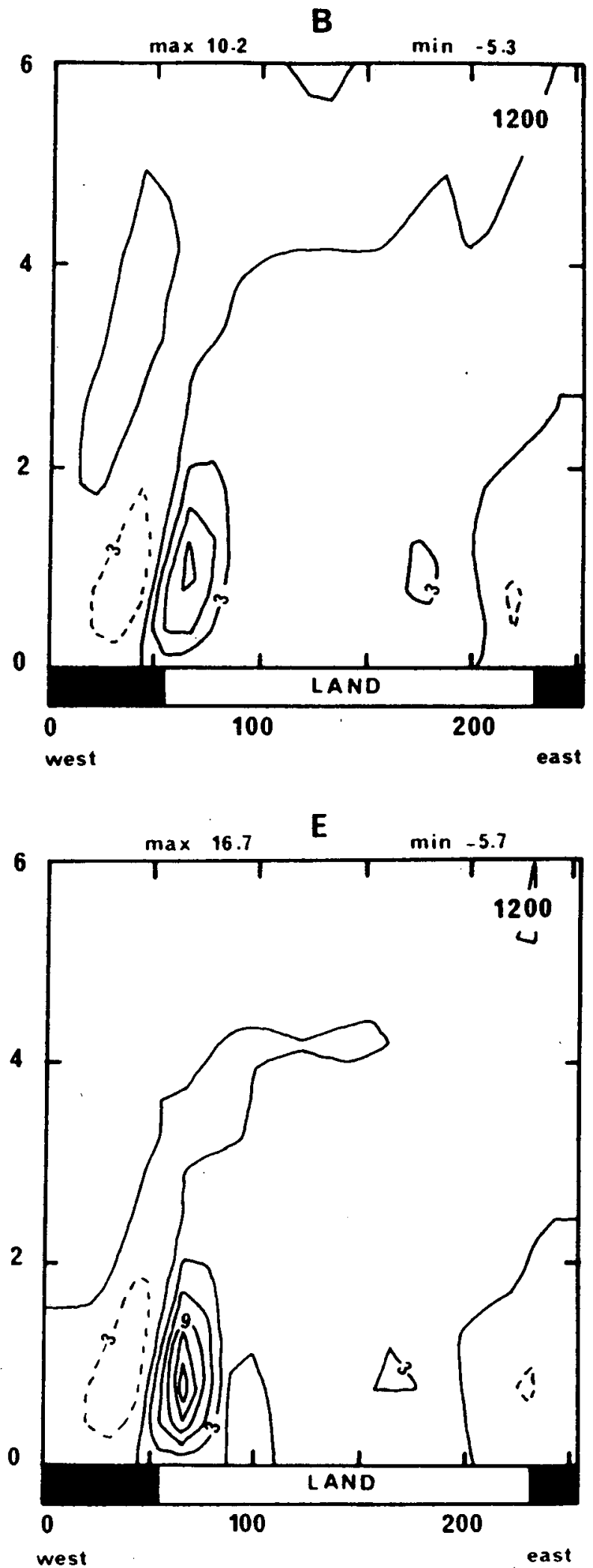

FIG. 19. As in Fig. 17 except for vertical velocity $\left(\mathrm{cm} \mathrm{s}^{-1}\right)$ at $1200 \mathrm{LST}$. 
1200

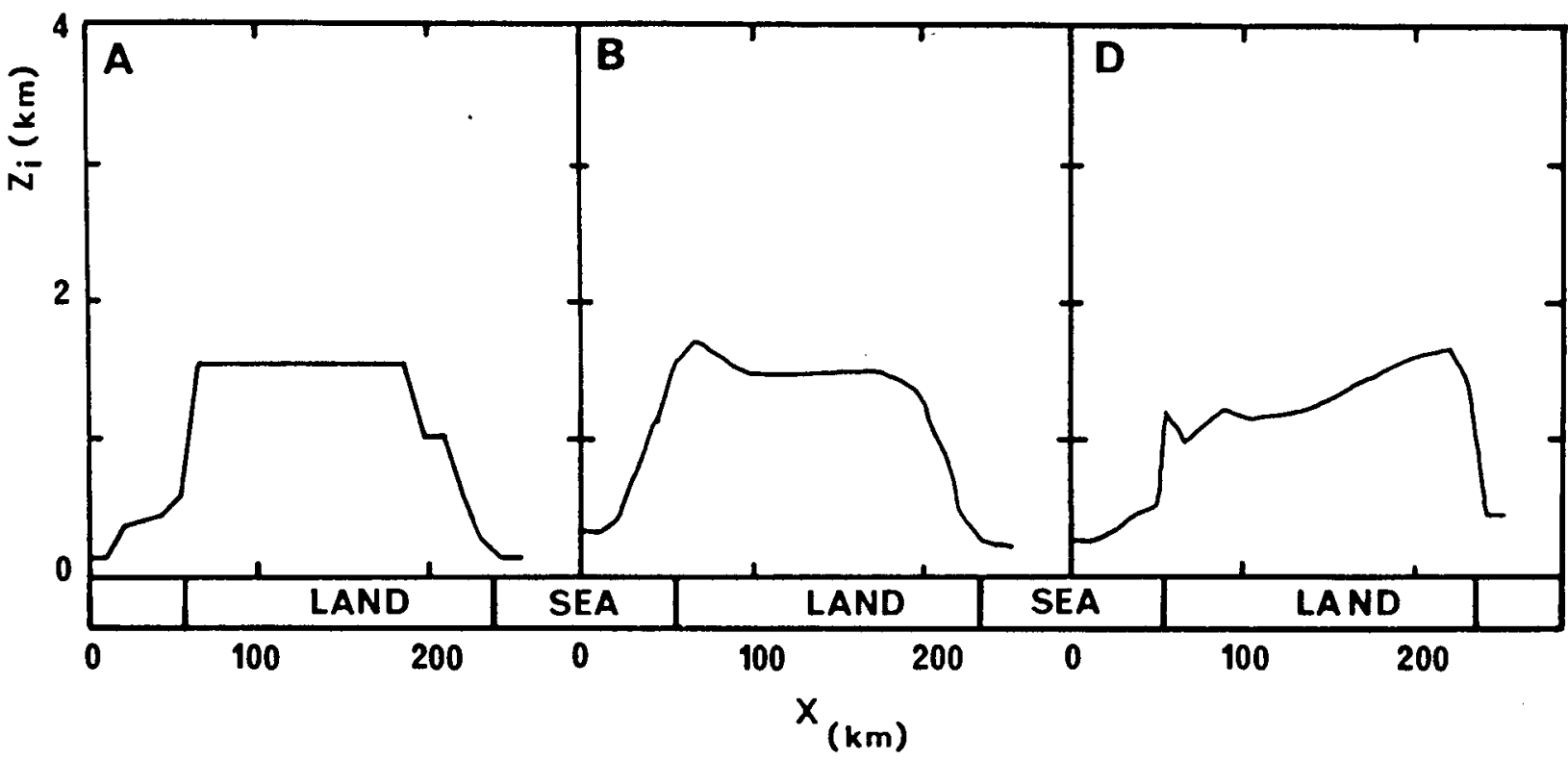

FIG. 20. Depth of the mixed layer $(\mathrm{km})$ predicted at 1200 LST along the line AA' of Fig. 8. Experiment A, TKE prognostic scheme; experiment B, Pielke and Mahrer (1975) scheme; experiment D, Pielke (1974) diagnostic scheme.

izontally inhomogeneous surface forcing using the 3D mesoscale model of Nickerson et al. (1986) to simulate the sea breeze flow over south Florida. The results obtained using the Therry-Lacarrère TKE parameterization are very encouraging and show the following:

(i) The comparison of the turbulence energy budget predicted by the TKE model and obtained using the third-order closure model of Brière (1987) reveals a good qualitative agreement and suggests that the TKE model gives a fair description of the turbulent structure for practical purpose;

(ii) The magnitude of the shear production in the transition region near the sea breeze front shows a localized, but significant, interaction between the turbulence field and the mesoscale breeze circulation.

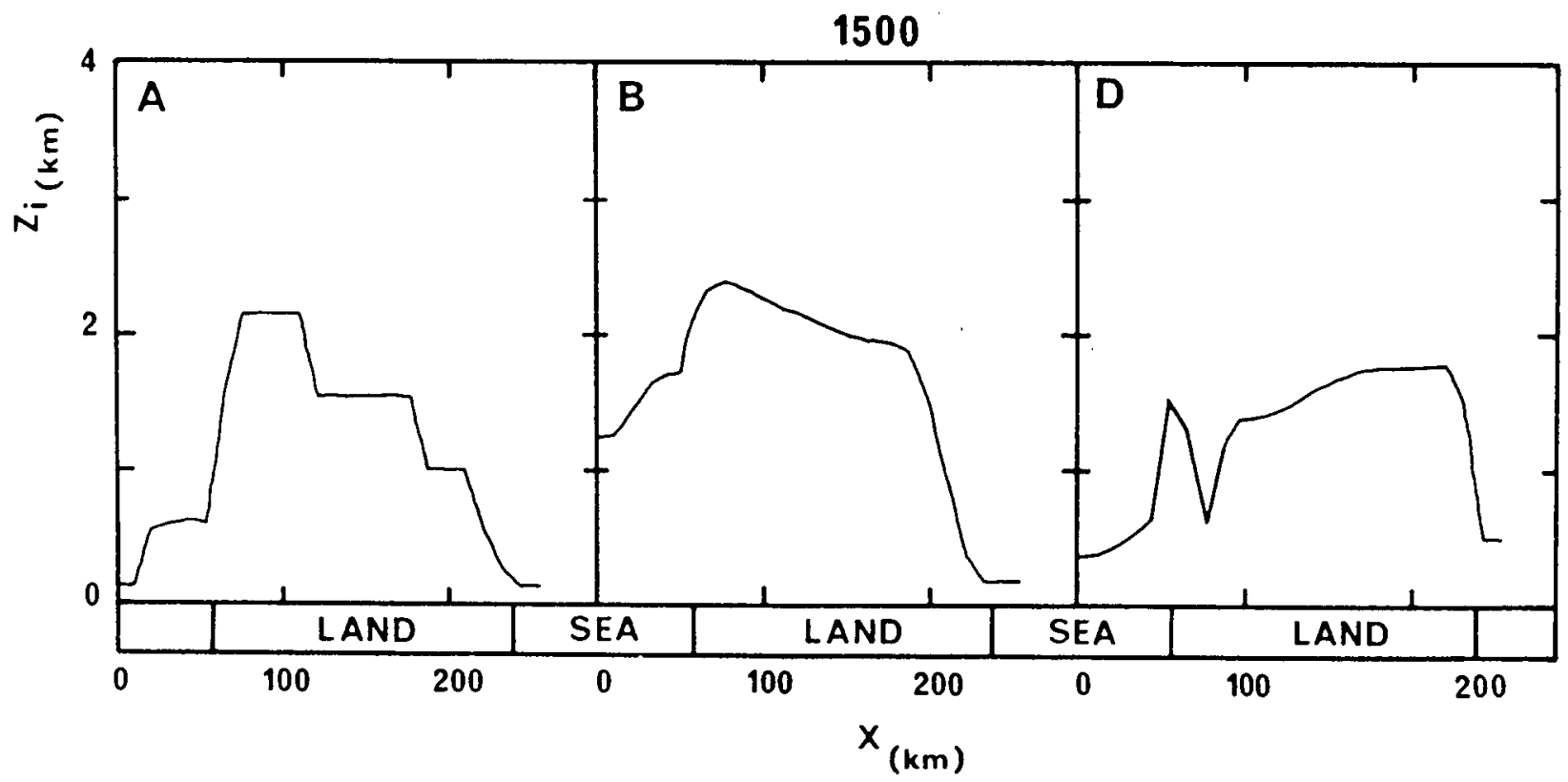

FIG. 21. As in Fig. 20 except at 1500 LST. 
Finally, the comparison between the results obtained with the TKE parameterization and those using the scheme of Pielke and Mahrer (1975) yield the following conclusions:

(i) as far as the mean variables are concerned, only slight differences are noticed between the two parameterizations;

(ii) the weaker Florida sea breeze circulation obtained with the TKE simulation is probably the result of a deeper turbulent mixing over the western half of the peninsula.

It is emphasized, however, that the weakest point of the previous discussions is probably the lack of reliable observation of the mesoscale structure of the turbulence. We plan an empirical test of the TKE scheme, along with further developments regarding the soil and vegetation parameterizations, using data from the HAPEX ${ }^{1}$ (André et al., 1986) field program aiming at a better knowledge and parameterization of the moisture budget at mesoscale. Further testing of the TKE parameterization should also be conducted against more realistic surface and topographic conditions. It is suggested that a useful test would be to examine whether the horizontal and vertical wind shears resulting from topographical forcing can lead to signifcant departures between the TKE parameterization and simpler prognostic PBL schemes.

Acknowledgments. The authors wish to thank $\mathrm{G}$. Therry, P. Lacarrère, Ch. Blondin and J. Y. Caneill for their helpful comments, especially during the early stages of the work. We have also greatly benefited from valuable suggestions by $A$. Maroquin and P. Bougeault. Our thanks also go to J. Duron who developed the graphic software and to Mrs. Bondoux, Guillot, Paquet and Squarise for preparing the manuscript. This work was supported by grants from Electricité de France, Institut National des Sciences de l'Univers (ATP-RA) and Programme National d'Etude du Climat (CNRS). Computer resources were provided by ECMWF (Reading, United Kingdom), CCVR (Palaiseau, France, project 3613) and Météorologie Nationale (Paris).

\section{APPENDIX}

\section{List of Symbols}

$$
\begin{aligned}
& A=\frac{g p}{R T_{v} \Pi \sigma^{\prime}} \\
& e \\
& E=\Pi e \\
& f \\
& F_{S}, F_{W}
\end{aligned}
$$$$
\text { scale factor (12) }
$$

turbulent kinetic energy

$g$

Coriolis parameter

vertical diffusion terms $[(10)$ and

(11), respectively]

acceleration of gravity $h$

$K_{H}, K_{M}$

$K_{\chi}$

$l_{K}$

$l_{\varepsilon}$

$p$
$p_{t}=100 \mathrm{mb}$

$q$

$Q_{0}$

$R$

$S=\Pi \theta$

$S_{V}=\Pi \theta_{v}$

$t$

$T$

$T_{V}=T(1+0.61 q)$

$u$

$u^{\prime}$

$u_{g}$

$u_{*}$

$v$

$v^{\prime}$

$v_{g}$

$w$

$w^{\prime}$

$W=\Pi q$

$w_{*}=\left(\frac{g}{\theta_{0}} Q_{0} Z_{i}\right)^{1 / 3}$

$x, y, z$

$Z_{i}$

$\gamma_{c g}=5 Q_{0} / w_{*} Z_{i}$

$\theta$

$\theta^{\prime}$

$\theta_{0}=280 \mathrm{~K}$

$\theta_{v}=\theta(1+0.61 q)$

$\nu$

$$
\dot{\nu}=\frac{d \nu}{d t}
$$$$
\mathrm{II}=p-p_{t}
$$

$\sigma=\frac{p-p_{t}}{\Pi}=\left(4 \nu-\nu^{4}\right) / 3$

$\sigma^{\prime}=\frac{d \sigma}{d \nu}$

$x$ depth of the surface layer

exchange coefficients for heat and momentum, respectively

exchange coefficient for variable $x$

mixing length scale (Therry and Lacarrère, 1983)

dissipation length scale (Therry and Lacarrère, 1983)

pressure

pressure at the top of the 3D model

water vapor mixing ratio

fluctuation of $q$

surface sensible heat flux

gas constant for air

time

temperature

virtual temperature

zonal component of the wind

fluctuation of $u$

zonal component of the geostrophic wind

friction velocity

meridional component of the wind

fluctuation of $v$

meridional component of the geostrophic wind

vertical velocity

vertical velocity fluctuations

convective velocity scale

zonal, meridional and vertical coordinates, respectively

mixed layer depth

temperature countergradient

potential temperature

fluctuation of $\theta$

reference temperature

virtual potential temperature

vertical coordinate in the $3 \mathrm{D}$ mesoscale model

vertical velocity in the $\nu$ system

\footnotetext{
' Hydrological and Atmospheric Pilot Experiment.
} 


\section{REFERENCES}

André, J. C., G. De Moor, P. Lacarrère, G. Therry and R. du Vachat, 1978: Modeling the 24-hour evolution of the mean and turbulent structures of the planetary boundary layer. J. Atmos. Sci., 35, 1861-1883.

— J. P. Goutorbe and A. Perrier, 1986: HAPEX-MOBILHY: A hydrologic atmospheric experiment for the study of water budget and evaporation flux at the climatic scale. Bull. Amer. Meteor. Soc., 67, 138-144.

Anthes, R. A., 1978: The height of the planetary boundary layer and the production of circulation in a sea breeze model. J. Atmos. Sci., 35, 1231-1239.

_- 1984: Enhancement of convective precipitation by mesoscale variations in vegetative covering in semiarid regions. J. Climate Appl. Meteor., 23, 541-554.

$\longrightarrow$, N. L. Seaman and T. T. Warner, 1980: Comparisons of numerical simulations of the planetary boundary layer by a mixedlayer and a multilevel model. Mon. Wea. Rev., 108, 365-376.

- D. Keyser and J. W. Deardorff, 1982: Further considerations on modeling the sea breeze with a mixed-layer model. Mon. Wea. Rev., 110, 757-765.

Blackadar, A. K., 1976: Modeling the nocturnal boundary layer. Preprints Third Symposium on Atmospheric Turbulence Diffusion and Air Quality. Raleigh, Amer. Meteor. Soc., 46-49.

- 1978: Modeling pollutant transfer during daytime convection. Preprints Fourth Symposium on Atmospheric Turbulence, Diffusion and Air Quality. Reno, Amer. Meteor. Soc., 443-447.

Bougeault, Ph., 1981: Modeling the trade-wind cumulus boundary layer. Part II: A high-order one-dimensional model. J. Atmos. Sci., 38, 2429-2439.

Brière, S., 1987: Energetics of daytime sea breeze circulation as determined from a two-dimensional, third-order turbulence closure model. J. Atmos. Sci., 44, 1455-1474.

Businger, J. A., 1973: Turbulent transfer in the atmospheric surface layer. Workshop on Micrometeorology, D. A. Haugen, Ed., Amer. Meteor. Soc., 67-100.

Clapp, R., and G. Hornberger, 1978: Empirical equations for some soil hydraulic properties. Water. Resour. Res., 14, 601-604.

Clarke, R. H., A. J. Dyer, R. R. Brook, D. G. Reid and A. J. Troup, 1971: The Wangara Experiment: Boundary layer data. Tech. Paper no. 19, Meteor. Phys., CSIRO, Australia.

Deardorff, J. W., 1974: Three-dimensional numerical study of the height and mean structure of a heated planetary boundary layer. Bound.-Layer Meteor., 7, 81-106.

Fiedler, B. H., 1984: An integral closure model for the vertical turbulent flux of a scalar in a mixed layer. J. Atmos. Sci., 41, 674680.

Keyser, D., and R. A. Anthes, 1977: The applicability of a mixedlayer model of the planetary boundary layer to real-data forecasting. Mon. Wea. Rev., 105, 1351-1371.

Lavoie, R. L., 1972: A mesoscale numerical model of lake-effect storms. J. Atmos. Sci., 29, 1025-1040.

Louis, J. F., 1979: A parametric model of vertical eddy fluxes in the atmosphere. Bound.-Layer Meteor., 17, 187-202.

McCumber, M. C., and R. A. Pielke, 1981: Simulation of the effects of surface fluxes of heat and moisture in a mesoscale numerical model. I: Soil layer. J. Geophys. Res., 86, 9929-9938.
McNider, R. T., and R. A. Pielke, 1981: Diumal boundary-layer development over sloping terrain. J. Atmos. Sci., 38, 2198-2212.

Mellor, G. L., 1977: The Gaussian cloud model relations. J. Atmos. Sci. 34, 356-358.

Mizzi, A. P., and R. A. Pielke, 1984: A numerical study of the mesoscale atmospheric circulation observed during a coastal upwelling event on 23 August 1972. Part I: Sensitivity studies. Mon. Wea. Rev., 112, 76-90.

Nickerson, E. C., and V. E. Smiley, 1975: Surface layer and energy budget parameterizations for mesoscale models. J. Appl. Meteor., 14, 297-300.

- E. Richard, R. Rosset and D. R. Smith, 1986: The numerical simulation of clouds, rain and airflow over the Vosges and Black Forest mountains: A meso- $\beta$ model with parameterized microphysics. Mon. Wea. Rev., 114, 398-414.

O'Brien, J. J., 1970: A note on vertical structure of the eddy exchange coefficient in the planetary boundary layer. J. Atmos. Sci., 27, 1213-1215.

Orlanski, I., 1975: A rational subdivision of scales for atmospheric processes. Bull. Amer. Meteor. Soc., 56, 527-530.

Pielke, R. A., 1974: A three-dimensional numerical model of the sea breezes over south Florida. Mon. Wea. Rev., 102, 115-139.

_ 1984: Mesoscale Meteorological Modeling. Academic Press, $612 \mathrm{pp}$.

- and Y. Mahrer, 1975: Representation of the heated planetary boundary layer in mesoscale models with coarse vertical resolution. J. Atmos. Sci., 32, 2288-2308.

- , and,- 1978 : Verification analysis of the University of Virginia three-dimensional mesoscale model prediction over south Florida for 1 July 1973. Mon. Wea. Rev., 106, 1568-1589.

Priestley, C. H. B., 1957: Convection from the earth's surface. Proc. Roy. Soc., 238(A), 287-304.

Stull, R. B., 1984: Transilient turbulence theory. Part I: The concept of eddy-mixing across finite distances. J. Atmos. Sci., 41, 33513367.

_ 1986: Transilient turbulence theory. Part III: Bulk dispersion rate and numerical stability. J. Atmos. Sci., 43, 50-57.

, and T. Hasegawa, 1984: Transilient turbulence theory. Part II: Turbulent adjustment. J. Atmos. Sci., 41, 3368-3379.

Sun, W.-Y., and Y. Ogura, 1979: Boundary-layer forcing as a possible trigger to a squall-line formation. J. Atmos. Sci., 36, 235-254.

Tapp, M. C., and P. W. White, 1976: A nonhydrostatic mesoscale model. Quart. J. Roy. Meteor. Soc., 102, 277-296.

Therry, G., and P. Lacarrère, 1983: Improving the eddy-kinetic energy model for planetary boundary layer description. Bound.-Layer Meteor., 25, 63-88.

Wyngaard, J. C., 1984: Toward convective boundary layer parameterization: A scalar transport module. J. Atmos. Sci., 41, 19591969.

Yamada, T., and G. Mellor, 1975: A simulation of the Wangara atmospheric boundary layer data. J. Atmos. Sci., 32, 2309-2329.

Zeman, O., 1979: Parameterization of the dynamics of stable boundary layers and nocturnal jets. J. Atmos. Sci., 36, 792-804.

Zhang, D., and R. A. Anthes, 1982: A high-resolution model of the planetary boundary layer. Sensitivity tests and comparisons with SESAME-79 data. J. Appl. Meteor., 21(11), 1594-1609.

scale structure and evolution of the 1977 Johnstown flood. Part I: Model description and verification. J. Atmos. Sci., 43, 19131943. 